ARTICLE

https://doi.org/10.1038/s41467-018-07787-6

\title{
SCL/TAL1 cooperates with Polycomb RYBP-PRC1 to suppress alternative lineages in blood-fated cells
}

Hedia Chagraoui ${ }^{1}$, Maiken S. Kristiansen ${ }^{1,8}$, Juan Pablo Ruiz ${ }^{1,2}$, Ana Serra-Barros ${ }^{1}$, Johanna Richter ${ }^{1}$, Elisa Hall-Ponselé ${ }^{1,9}$, Nicki Gray ${ }^{3}$, Dominic Waithe (1) ${ }^{4}$, Kevin Clark ${ }^{5}$, Philip Hublitz (1) ${ }^{6}$, Emmanouela Repapi (1) ${ }^{3}$, Georg Otto (1) 1,7,10, Paul Sopp ${ }^{5}$, Stephen Taylor ${ }^{3}$, Supat Thongjuea ${ }^{3,7}$, Paresh Vyas (i) ${ }^{1,7}$ \& Catherine Porcher (iD ${ }^{1}$

During development, it is unclear if lineage-fated cells derive from multilineage-primed progenitors and whether active mechanisms operate to restrict cell fate. Here we investigate how mesoderm specifies into blood-fated cells. We document temporally restricted coexpression of blood (Scl/Tal1), cardiac (Mesp1) and paraxial (Tbx6) lineage-affiliated transcription factors in single cells, at the onset of blood specification, supporting the existence of common progenitors. At the same time-restricted stage, absence of SCL results in expansion of cardiac/paraxial cell populations and increased cardiac/paraxial gene expression, suggesting active suppression of alternative fates. Indeed, SCL normally activates expression of co-repressor ETO2 and Polycomb-PRC1 subunits (RYBP, PCGF5) and maintains levels of Polycomb-associated histone marks (H2AK119ub/H3K27me3). Genome-wide analyses reveal ETO2 and RYBP co-occupy most SCL target genes, including cardiac/paraxial loci. Reduction of Eto2 or Rybp expression mimics Scl-null cardiac phenotype. Therefore, SCLmediated transcriptional repression prevents mis-specification of blood-fated cells, establishing active repression as central to fate determination processes.

\footnotetext{
${ }^{1}$ Medical Research Council Molecular Haematology Unit, University of Oxford, John Radcliffe Hospital, Oxford OX3 9DS, UK. ${ }^{2}$ Haematology Branch, National Heart, Lung and Blood Institute, National Institutes of Health, Bethesda, MD 20892, USA. ${ }^{3}$ Computational Biology Research Group, University of Oxford, John Radcliffe Hospital, Oxford OX3 9DS, UK. ${ }^{4}$ Wolfson Imaging Centre, University of Oxford, John Radcliffe Hospital, Oxford OX3 9DS, UK. ${ }^{5}$ FACS Facility, University of Oxford, John Radcliffe Hospital, Oxford OX3 9DS, UK. ${ }^{6}$ Genome Engineering Facility, Medical Research Council Weatherall Institute of Molecular Medicine, Radcliffe Department of Medicine, University of Oxford, John Radcliffe Hospital, Oxford OX3 9DS, UK. ${ }^{7}$ Oxford National Institute for Health Research, Biomedical Research Centre, Haematology Theme, Oxford University Hospital, Oxford OX3 9DU, UK. ${ }^{8}$ Present address: Medimmune, Granta Park, CB21 6GH Cambridge, UK. ${ }^{9}$ Present address: MRC Centre for Regenerative Medicine, SCRM Building, The University of Edinburgh, Edinburgh EH16 4UU, UK. ${ }^{10}$ Present address: Genetics and Genomic Medicine, UCL Great Ormond Street Institute of Child Health, London WC1N 1EH, UK. Correspondence and requests for materials should be addressed to C.P. (email: catherine.porcher@imm.ox.ac.uk)
} 
$\mathrm{n}$ embryonic development, early cell fate decisions occur at gastrulation when epiblast cells migrate through the primitive streak (PS) and specify into germ layers ${ }^{1-4}$. A characteristic of cells undergoing specification is their developmental plasticity, as revealed by their ability to respond to changing environmental or intrinsic cues and adopt different fates, suggesting multipotency ${ }^{3}$. Cellular identity becomes locked after egression from the PS. Therefore, acquisition of lineage-specific features is likely to coincide with progressive loss of the ability to generate alternative lineages through restriction of cell potential. Whether emerging tissue-specific transcriptional regulators driving lineage specification also actively control these restriction processes is unclear.

Specification of blood cells from $\mathrm{FLK}^{+}{ }^{+}$mesodermal progenitors is a model of lineage development. The initial steps of this process are under control of the transcription factor (TF) SCL/TAL1, placing it at the apex of the haematopoietic transcriptional hierarchy, ${ }^{5,6}$. Interestingly, absence of SCL not only leads to complete block in haematopoiesis 7,8 , but also to expansion of the heart field in zebrafish embryos and ectopic cardiomyocyte production from mouse yolk sac and ES cell-derived endothelium, revealing latent cardiac potential in blood/endothelial progenitors ${ }^{9-11}$. Conversely, forced expression of $\mathrm{Scl}$ mRNA expands blood and endothelial tissues at the expense of myocardial tissues in vivo ${ }^{12}$ and in vitro ${ }^{13}$. This highlights a close developmental relationship between blood and cardiac lineages and supports the notion of plasticity.

However, it is unclear if common, multilineage-primed blood/ cardiac mesodermal progenitors exist and whether active repression mechanisms are established in blood-fated cells to prevent development of the cardiac lineage. Two recent studies propose contrasting mechanisms. Molecular analyses of ES cellderived $\mathrm{FLK}^{+}{ }^{+}$cells show that SCL occupies a subset of enhancers regulating cardiac-specific genes, suggesting this makes these enhancers unavailable for activation by cardiac-specific TFs ${ }^{11}$. In contrast, single cell analyses from mouse $\mathrm{Scl}^{-1-}$ embryos failed to detect increased cardiac gene expression in $\mathrm{Scl}^{-1-} \mathrm{FLK}^{+}$cells, questioning the role of SCL in suppressing the cardiac fate ${ }^{14}$. However, it is unclear if the two studies were conducted at similar developmental time points and examined functionally equivalent $\mathrm{FLK}^{+}$cells.

Mechanistically, SCL is both an activating and repressive TF. It acts within multi-protein complexes containing a core of four proteins (SCL/E47/LMO2/LDB1) and co-factors/chromatin remodelling proteins conferring activating (P300/CBP) or repressive (mSIN3A, ETO2, GFI1B) activities ${ }^{5,15}$.

Chromatin remodelling proteins, like repressive Polycomb (PcG) complexes, play critical functions in early development. PcG complexes control pluripotency and differentiation of embryonic stem (ES) cells and, in vivo, are required for survival and organogenesis ${ }^{16}$. Two PcG complexes (PRC1/PRC2) usually work in concert. Their activities are associated with distinct histone modifications: H2AK119 monoubiquitination (H2AK119ub, PRC1) and H3K27 trimethylation (H3K27me3, PRC2). Several PcG complexes exist that all contain enzymatic activities (PRC1 ubiquitin ligases; PRC2 methyltransferases), but vary in their overall composition. PRC1 complexes include ubiquitin ligase modules (RING1A/1B and PCGF1-6) and CBX or RYBP/YAF2 proteins in a mutually exclusive manner ${ }^{17}$. PcG complexes commonly bind $\mathrm{CpG}$ islands at gene promoters ${ }^{18}$.

To get further insight into the mechanisms underlying blood specification, we used murine ES cell differentiation cultures to follow production of mesoderm-derived blood-fated cells. We report a series of molecular events that occur over a restricted, one-day developmental time-window, at the onset of blood specification. We first document multi-lineage (blood/cardiac/paraxial) priming in single mesodermal cells. We then show that absence of SCL leads to rapid conversion of blood-fated cells into functional cardiac and paraxial cells, in agreement with the notion of cellular plasticity. To suppress alternative lineages, SCL activates expression of select repressors (ETO2 and PRC1 members) and creates a global repressive epigenetic environment, in parallel to activating blood/endothelial-related genes to promote haematopoietic specification. These processes form the basis of lineage selection and highlight the prevalence of active transcriptional repression in cell fate choices.

\section{Results}

Transient co-expression of distinct lineage-affiliated TFs. Mouse ES cell/embryoid body (EB) differentiation cultures recapitulate major embryonic developmental processes ${ }^{19}$ (Fig. 1a, top). Following production of $\mathrm{Fg} 5^{+}$epiblast-like cells, Brachyury + mesoderm develops from day 2.5 (Fig. 1a, right). From day 3 , expression of VEGFA receptor, Flk1, marks the emergence of mesodermal progenitors at the origin of the endothelial and blood lineages $^{20}$. Day $3 / 3.5$ sees robust expression of tissue-specific regulators of distinct mesoderm-derived lineages: $\mathrm{Scl}$ (haematopoietic ${ }^{5}$ ), Mesp1 ( ardiac $^{21}$ ) and Tbx6 (paraxial ${ }^{22}$ ) (Fig. 1a, bottom). This stage corresponds to the development of nascent/ posterior mesoderm in the primitive streak of day E7/7.5 mouse embryos (Supplementary Fig. 1) and marks the onset of lineage specification in the ES/EB model.

To test if multilineage-primed mesodermal progenitors exist, we asked if $S c l$, Mesp1 and Tbx6 were co-expressed in the same cells by single molecule mRNA (smRNA) FISH. We designed probe libraries for each mRNA species, co-stained day 3 to day 4.5 EB cells and quantitated the number of single mRNA molecules (foci) in individual cells (Fig. 1b). The average foci number/cell for each mRNA target (Fig. 1c) followed the expression pattern of the corresponding mRNA species in cell populations (Fig. 1a, bottom). When assessing co-expression of the three markers, we observed triple (Scl/Mesp1/Tbx6) and double (Scl/Mesp1, Scl/Tbx6) positive cells (Fig. 1d, e, Supplementary Fig. $2 \mathrm{a}-\mathrm{c}$ ). The proportion of these cells amongst $\mathrm{Scl}$ expressing cells increased from day 3 to day 3.5 (20-35\% of total $\mathrm{Scl}$-positive cells, Fig. 1d), but decreased thereafter ( 9 and $3 \%$ at days 4 and 4.5, Fig. 1d). Because Mesp1 broad expression in early gastrulating embryos suggests it could label mesodermal lineages other than cardiac ${ }^{23,24}$, data obtained with Mesp1 were confirmed with another cardiac-defining marker, Gata4 (Supplementary Fig. 2d). The high proportion of Scl/Mesp1/Gata4-coexpressing cells amongst day $3.5 \mathrm{Scl} / \mathrm{Mesp} 1$-positive cells (87\%) validated Mesp1 as a marker of the cardiac lineage in Scl-expressing cells, at the developmental timepoint examined. Thus, $S c l, M e s p 1$ and Tbx6 are co-expressed over a tight developmental time-window. At a single cell level, the decrease in double and triple positive cells in day 4/4.5 EBs was accompanied by increased numbers of Scl-expressing cells ( 45 and $51 \%$ of total EB cells).

We then correlated the level of $S c l, M e s p 1$ and $T b x 6$ expression in day 3.5 single cells. High $(\mathrm{H})$ numbers of $S c l$ foci (21-139) were preferentially associated with no (0-5) or low (6-20 foci) expression of Mesp1 or Tbx6 (example cell (i), Fig. 1f, g, Supplementary Fig. 2e), whilst highest numbers of Mesp1 (21-166) or Tbx6 (21-40) foci preferentially occurred in cells negative (N) for $\mathrm{Scl}$ (cells (ii) and (iii), Fig. 1f, g). Similarly, we never detected co-expression of the three genes at high levels (Supplementary Fig. 2f).

In conclusion, co-expression of $S c l / M e s p 1 / T b x 6, S c l / M e s p 1$ and $S c l / T b x 6$ preferentially occurs at low mRNA levels in a subset of Scl-expressing cells at day $3 / 3.5$, consistent with multi-lineagepriming of distinct mesodermal lineages. Subsequently, as $\mathrm{Scl}$ mRNA levels increase, reflecting consolidation of the blood programme, expression of alternative lineage-specific regulators is lost. 


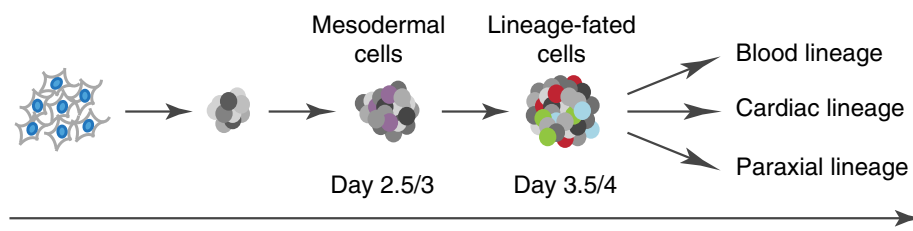

ES cells
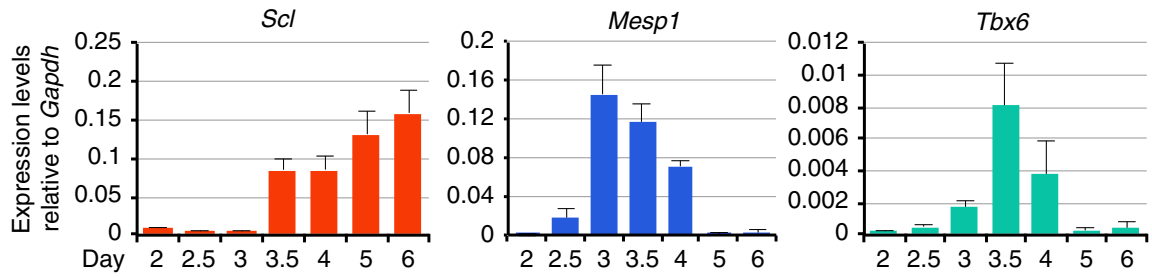

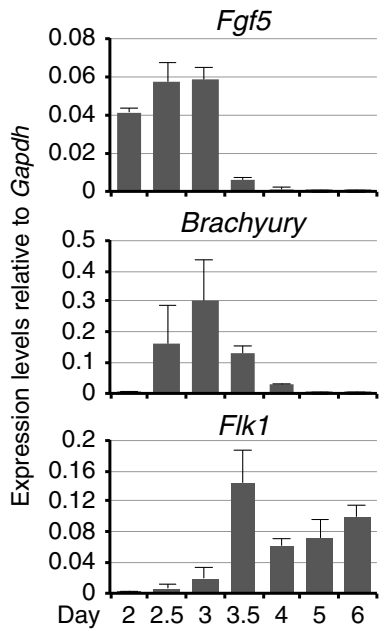

b

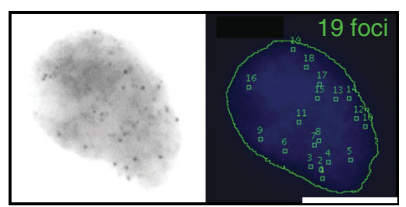

C

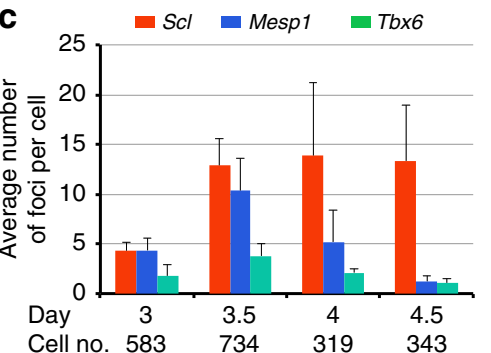

d Day 3

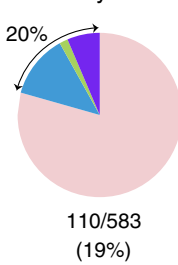

acl/Mesp1/Tbx6 $\square$ Scl/Tbx6 $\quad$ Scl/Mesp1 Scl
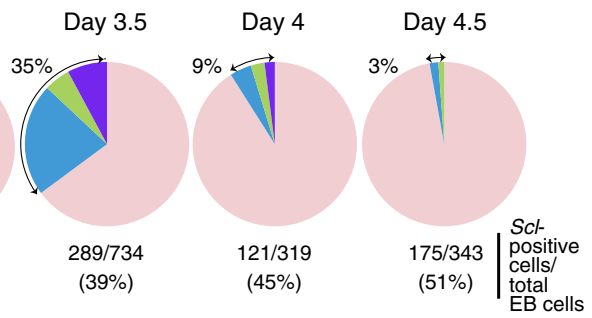

Cell no, $583 \quad 734 \quad 319 \quad 343$
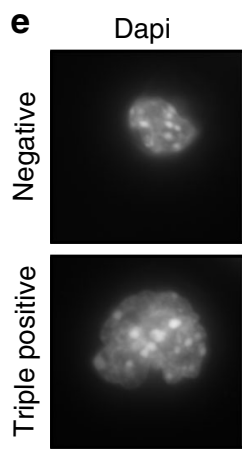

g
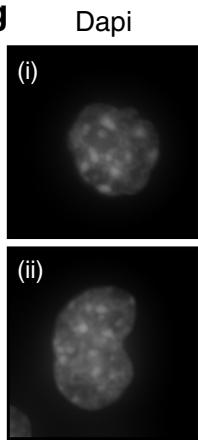
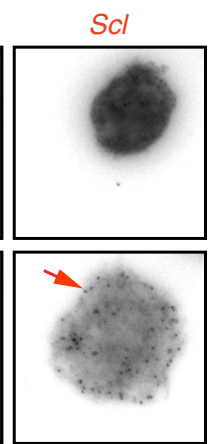

$\mathrm{Scl}$
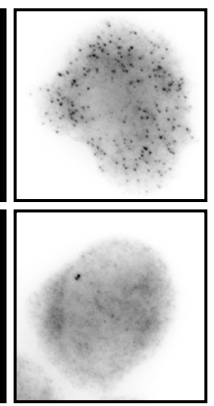

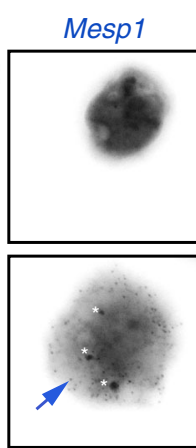

Mesp1

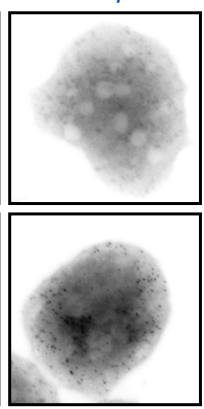

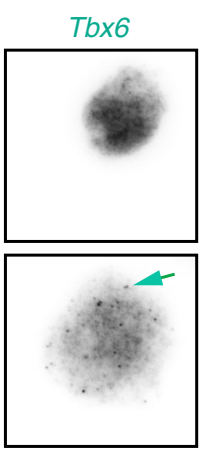

Merge
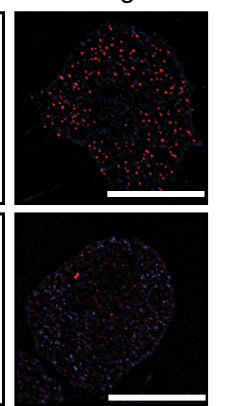

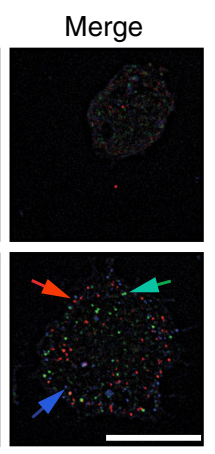

f

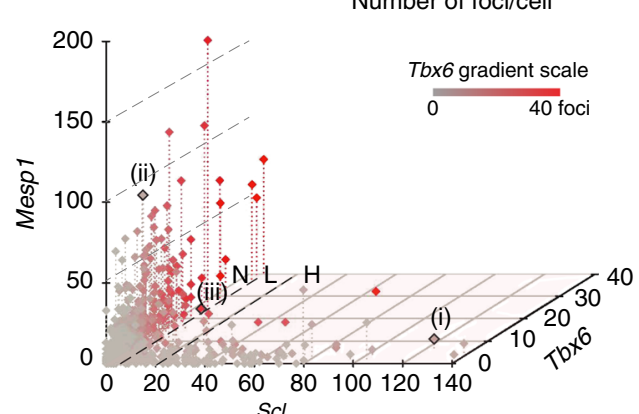

Dapi

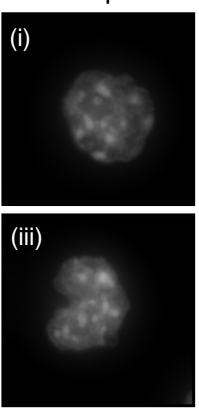

Tbx6

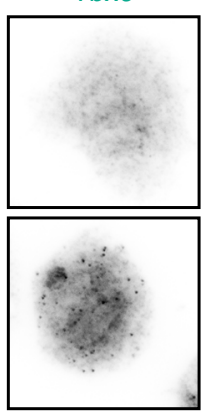

Merge

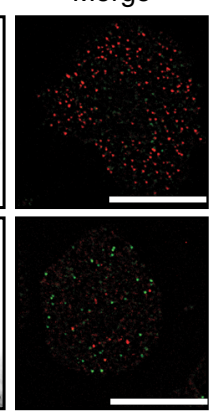

Immunophenotypic conversion of $\mathrm{Scl}^{-/-}$FLK1 positive cells. Having established the presence of multi-lineage primed cells, we next investigated how lineage potentials resolve. We studied blood fate selection in day $3.5 \mathrm{EBs}$, when $35 \%$ of Scl-expressing cells co-express Mesp1 and/or Tbx6 mRNA. To identify lineage output, we monitored expression of cell surface markers FLK1 and PDGFR $a$ that separate mesodermal populations with distinct functional potential ${ }^{25-28}$ (Fig. 2a). Multiple mesodermal potentials are initially found in the FLK $1^{+} \mathrm{PDGFRa}^{+}$(double positive,
DP) compartment. FLK1 single positive (F-SP) cells contain lateral plate mesoderm with haematopoietic/endothelial potential and PDGFRa single positive (P-SP) cells contain paraxial and cardiac potential.

Flow cytometry staining for FLK1, PDGFRa (Fig. 2bi, Supplementary Fig. 3a) and SCL (Fig. 2bii) showed that 19\% $( \pm 8)$ of day 3.5 EB cells expressed SCL. $80-93 \%$ of SCL-expressing cells were in the F-SP lateral plate compartment (Fig. 2biii, left panels). Conversely, 50-62\% of the F-SP population expressed 
Fig. $1 \mathrm{Scl}$, Mesp1 and Tbx6 are transiently co-expressed in single cells. a Top, Schematic of ES/EB in vitro differentiation. Right and bottom, RT-qPCR gene expression analyses from RNA isolated from day 2-6 EB cells $(n=3$, mean \pm SD). $\mathbf{b}$ Example of detection of single mRNA molecules (foci) in a single EB cell by smRNA FISH. Left, raw image. Right, foci detection (green squares) with ImageJ Macro. c Average number of mRNA molecules/cell determined by smRNA FISH for Scl, Mesp1 and Tbx6, from day 3 to $4.5 \mathrm{EBs}$. Cell no.: number of cells analysed at each time point. d Distribution of Scl-positive cells (Scl/Mesp1/Tbx6, Scl/Tbx6, Scl/Mesp1, Scl-only) in day 3, 3.5, 4, and 4.5 EBs. Total number of EB cells and percentage of Scl-positive cells are indicated for each timepoint. Cells are considered positive for a marker when harbouring 6 or more foci. e smRNA FISH images showing a negative cell (top panel) and a cell positive for Scl, Mesp1 and Tbx6 (bottom panel) from day $3.5 \mathrm{EBs}$. Arrows indicate typical foci for each mRNA species; white star, background signal. $\mathbf{f}$ Significant non-linear negative correlation of expression between Scl and Mesp1 and Scl and Tbx6. Each dot represents a cell from day $3.5 \mathrm{EBs}$ (total cells: 734). $X$-axis, number of $\mathrm{Scl}$ foci per cell; $Y$-axis, Mesp1 foci; Z-axisTbx6 foci. Numbers of Tbx6 foci are also indicated by a grey-red scale. Examples of Scl/ Mesp1 and Scl/Tbx6 negatively correlated cells (i, ii, iii; Fig. 1g) are marked. Correlation coefficients: Scl/Mesp1: $-0.2379, p$-value < 0.0001, 95\% confidence interval (Cl): $-0.3117 /-0.1612$; Scl/Tbx6: $-0.1504, p$-value < 0.002, 95\% Cl -0.2274/-0.07151. N, L, H: number of Scl foci/cell (N, negative; L, low (6-20 foci); H, high (21-139 foci)). g smRNA FISH images of representative cells showing Sclhigh/Mespllow (i, left) and Scligh $/$ Tbx $^{\text {low }}$ (i, right), Sclow/Mesp ${ }^{\text {high }}$ (ii), Sclow/Tbx6high (iii) mRNA foci. Scale bars: $11.3 \mu \mathrm{m}$. See also Supplementary Fig. 2

SCL (Fig. 2biii, right panels). To study the fate of SCL-expressing cells, we FACS-sorted day 3.5 F-SP cells (Supplementary Fig. 3b), re-aggregated the cells into EBs and, after $24 \mathrm{~h}$, re-analysed FLK1/ PDGFRa expression (Fig. 2c, left, wild-type (WT) panel). 60-70\% of the F-SP cells differentiated into FLK1-PDGFRa ${ }^{-}$(DN, double negative) maturing haematopoietic cells ${ }^{29,30}$. However, about $10 \%$ of F-SP cells acquired PDGFRa expression and were detected in the DP/P-SP compartments. These PDGFRa ${ }^{+}$cells may represent rare cells with higher expression of Mesp1 and Tbx6 than Scl (ScllowMesp ${ }^{h i}$, Sclow Tbx6 ${ }^{\text {hi }}$ and Sclow Mesp ${ }^{\text {hi }} T b x 6^{\text {hi }}$ Supplementary Fig. 2e-f), suggesting there may be competition between blood and non-blood fates within multilineage-primed cells, dependent on Scl, Mesp1 and Tbx6 levels. Therefore, absence of SCL might increase the number of cells adopting alternative fates.

To test this hypothesis, we isolated F-SP cells from $\mathrm{Scl}^{-/-}$day 3.5 EBs (Fig. 2d) and subjected them to the same re-aggregation assay employed with WT cells. After $24 \mathrm{~h}, \mathrm{Scl}^{-/-} \mathrm{F}-\mathrm{SP}$ cells exhibited a markedly different immunophenotypic pattern (Fig. 2c, left, $\mathrm{Scl}^{-/-}$panels). The majority of $\mathrm{Scl}^{-/}$F-SP cells acquired PDGFR $\alpha$ expression and were DP or P-SP, consistent with the hypothesis that they may have acquired non-blood fates.

To validate these observations, we generated two Scl:mCherry reporter ES cell lines expressing either WT SCL (Scl:mCherry) or a non-functional form of SCL missing the vital basic helix-loophelix domain ${ }^{31}\left(S l^{\Delta / \Delta}: m\right.$ Cherry, Supplementary Fig. 3c-f). Immunophenotyping of day $4.5 \mathrm{~EB}$ cells showed that $47.5 \%$ of Scl:mCherry cells and $20.5 \%$ of $S_{c l}{ }^{\Delta / \Delta}: m$ Cherry were mCherry ${ }^{+}$ (Fig. 2e, left panels); this difference is likely due to SCL's positive transcriptional auto-regulation ${ }^{32}$. Importantly, a dramatic $76.8 \%$ of $S c{ }^{\Delta / \Delta}: m$ Cherry ${ }^{+}$cells expressed PDGFRa (DP/P-SP compartments), as opposed to $8.3 \%$ of Scl:mCherry ${ }^{+}$cells (Fig. 2e, right panels), confirming our earlier results.

A key observation from the smRNA FISH experiments was the tight temporal control of transcriptional priming of blood, cardiac and paraxial lineages, peaking at day 3.5 and greatly reduced by day 4.5 (Fig. 1d, Supplementary Fig. 2b). This suggested that cells could alter mesodermal fates maximally at day 3.5. Indeed, when compared to day $3.5 \mathrm{Scl}^{-1}-\mathrm{F}-\mathrm{SP}$ cells, a greatly decreased number of day $4.5 \mathrm{Scl}^{-/-} \mathrm{F}$-SP cells acquired low level PDGFRa expression in the re-aggregation assay (Fig. 2c, right panels). Therefore, temporal restriction of multi-lineage priming correlates with the tight temporal window in which F-SP cells acquire PDGFRa expression.

Absence of SCL increases adoption of alternative fates. We next asked if gain in PDGFRa expression in absence of SCL reflected increased numbers of cells adopting non-blood cell fates. We first replated day 3.5 WT and $\mathrm{Scl}^{-}{ }^{-}$mesodermal populations (P-SP/ $\mathrm{DP} / \mathrm{F}-\mathrm{SP})$ in conditions promoting cardiac development. Cardiac cell output was assessed by immunofluorescence staining for cardiac troponin (cTNT, Fig. 3a) and mRNA analysis (Tnnt2/Tnni3/Myh6, Fig. 3b). Strikingly, significantly more cardiac cells were detected in the $\mathrm{Scl}^{-/-}$vs. WT P-SP populations, showing a rapid functional conversion of $\mathrm{Scl}^{-/-}$cells. We confirmed ectopic cardiomyocyte production in vivo from $\mathrm{Scl}^{-1-}$ mouse embryos. Obvious foci of cardiac $\mathrm{cTNT}^{+}$cells were detected in day E9.5 $\mathrm{Scl}^{-/-}$, but not WT, yolk sacs (Fig. 3c). Next, we tested the paraxial potential of WT and $\mathrm{Scl}^{-}{ }^{-}$cells by replating day 3.5 fractionated or whole EB cells in chondrogenic conditions. Cultures from $\mathrm{Scl}^{-/-} \mathrm{P}-\mathrm{SP} / \mathrm{DP}$ populations exhibited increased formation of chondrogenic-specific glycosaminoglycan clusters (Alcian blue staining, Fig. 3d), and increased expression of the early chondrogenic marker, Sox $9^{33}$, (Fig. 3e), when compared to WT cells. Similarly, cultures from $\mathrm{Scl}^{-\%} \mathrm{~EB}$ cells showed more cells positive for COLLAGEN IIA, major downstream target of Sox $9^{34}$, and increased ColIIa mRNA expression (Fig. 3f). Increased chondrogenic potential was confirmed in vivo from $\mathrm{Scl}$ null yolk sacs (Fig. 3g). As controls, haematopoietic cells developed only from WT, but not $\mathrm{Scl}^{-/}$, F-SP/DP populations, in blast colony assays ${ }^{35}$ (Fig. 3h). Therefore, in absence of SCL, functional cardiac and paraxial PDGFRa ${ }^{+}$populations expand in day 3.5 EBs.

Finally, to further validate the hypothesis that only $S c l$ low expressing cells can adopt a non-blood fate, we purified day 3.5 Scl:mCherrylow and Scl:mCherry high cells and tested their developmental potential in re-aggregation and cardiac assays. As expected, $24 \mathrm{~h}$ after purification, the majority of the mCherrylow cells became $m$ Cherry high and FLK1/PDGFRa DN, pursuing their normal hematopoietic differentiation trajectory (Fig. 3i, Supplementary Fig. 3g). Remarkably, however, day 3.5 Scl:mCherrylow, but not Scl:mCherryhigh, cells generated a PDGFRa-positive population in the re-aggregation assay (7.9\%, Fig. 3i). Confirming the adoption of alternative fates by cells expressing low levels of $S c l$, cTNT-positive cardiomyocytes were exclusively observed from Scl:mCherry ${ }^{\text {low }}$ cells in cardiac cultures (Fig. 3j). Therefore, cell fate decisions critically depend on $S c l$ mRNA thresholds.

In conclusion, our data identify a temporally restricted conversion of day $3.5 \mathrm{Scl}^{-/-} \mathrm{F}-\mathrm{SP}$ cells into functional cardiac cells, in line with previous data showing ectopic emergence of PDGFRa cells with a cardiac expression programme in $\mathrm{Scl}^{-/-}$ yolk sac ${ }^{10}$. We extend these observations by showing that paraxial lineage cells are also produced from day $3.5 \mathrm{Scl}^{-1-} \mathrm{F}$-SP cells. Critically, the tight time-window during which non-blood lineages are produced in absence of SCL coincides with the restricted developmental period revealing multilineage-primed mesodermal cells.

SCL controls expression of transcriptional repressors. We next defined the molecular mechanism leading to acquisition of nonblood cell fates in absence of SCL. RNA sequencing revealed 2036 
a

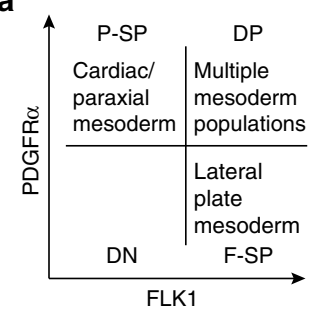

b
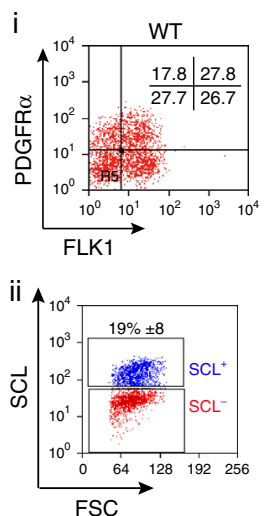

c
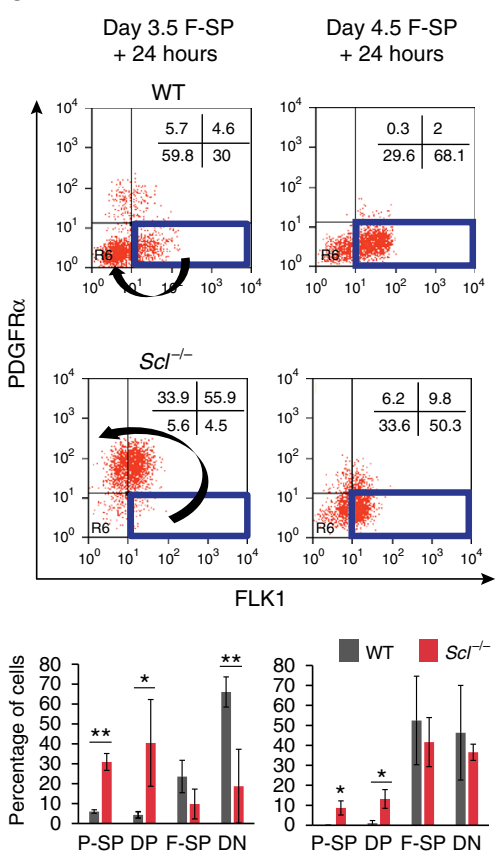

e

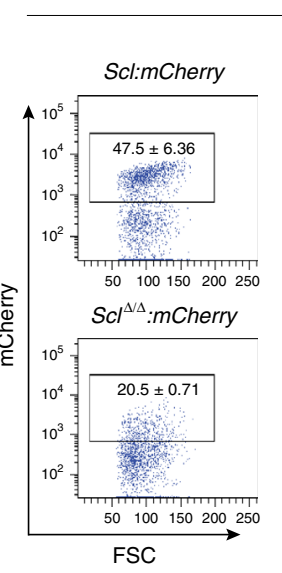

Day 4.5

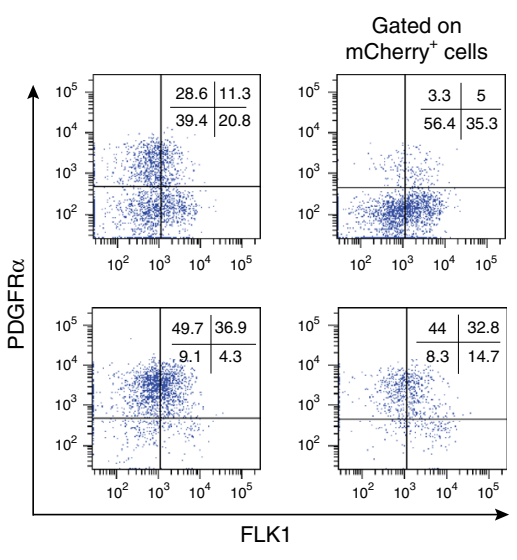

Scl:mCherry

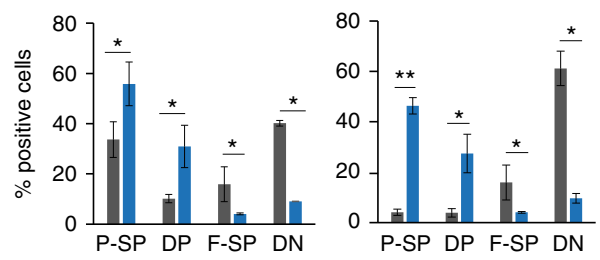

$S c l^{\Delta \Delta}: m$ Cherry

iii

Same as in bi, showing

$\begin{array}{cc}\text { Same as in bi, } & \% \text { of } \mathrm{SCL}^{+} \text {cells } \\ \text { gated on } \mathrm{SCL}^{+} \text {cells } & \text { in each fraction }\end{array}$

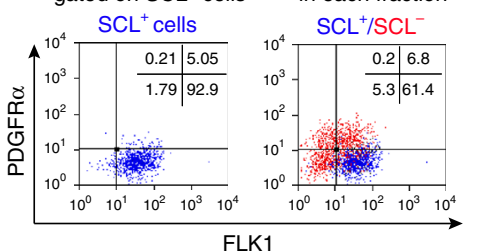

d
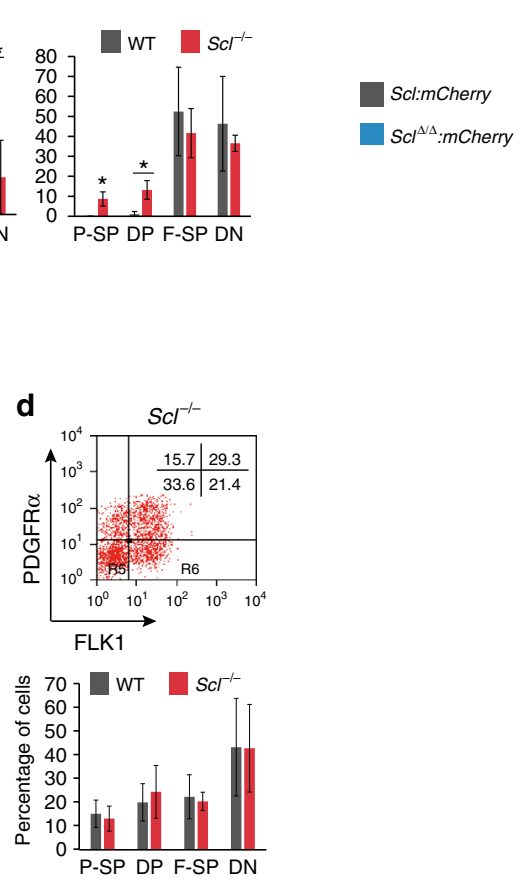

Fig. 2 Immunophenotypic conversion of Scl-null FLK1-single positive cells. a Days 3.5/4 ES cell-derived mesodermal populations are functionally defined by expression of cell surface markers FLK1 and PDGFR $\alpha$. P-SP, PDGFR $\alpha$ single positive; DP, double positive; F-SP, FLK1 single positive; DN, double negative. b (i) Distribution of FLK1- and PDGFR $\alpha$-positive populations in WT day 3.5 EBs. (ii) SCL protein expression in day 3.5 WT EBs (intra-cellular FACS). (iii) Left, top, distribution of FLK1/PDGFR $\alpha$-positive cells shown in bi and gated on SCL-positive cells; bottom, mean of 9 independent experiments; Right, top, distribution of $\mathrm{SCL}^{+}$cells in each FLK1/PDGFR $\alpha$ compartment. Blue events: $\mathrm{SCL}^{+}$cells, red events: $\mathrm{SCL}^{-}$cells; bottom, mean of 9 independent experiments. c Re-aggregation assays. F-SP populations were FACS-sorted from WT and Scl/- EBs (left panels, day 3.5; right panels, day 4.5), allowed to re-aggregate for $24 \mathrm{~h}$ and analysed for FLK1/PDGFR $\alpha$ expression. The arrows show the different immunophenotypic conversions of WT and Scl/- cells at day $3.5+24 \mathrm{~h}$. Bottom, mean of two independent experiments. d Top, distribution of FLK1-positive and PDGFR $\alpha$-positive populations in Scl/- day $3.5 \mathrm{EBs}$; bottom, comparison with WT cells (shown in bi), mean of 4 independent experiments. e Scl:mCherry and $S c \mid \Delta / \Delta$ :mCherry reporter lines analysed in day 4.5 EBs. Representative FACS plots of mCherry expression (left), FLK1/PDGFR $\alpha$ expression (middle) and FLK1/PDGFR $\alpha$ plots gated on mCherry-positive cells (right) are shown. Below, mean of 2 independent experiments. Mean \pm SD is shown in b-e; student's $t$-test, ${ }^{*} p<0.05,{ }^{\star \star} p<0.01$. Scale bars, $100 \mu \mathrm{m}$. See also Supplementary Fig. 3

differentially expressed genes (DEGs) between day $3.5 \mathrm{WT}$ and $\mathrm{Scl}^{-/-} \mathrm{FLK}^{+}$cells (Fig. 4a). Consistent with the functional cellular output (Fig. 3a-h), the 1038 genes normally activated by SCL (upregulated in WT versus $\mathrm{Scl}^{-9}$ - cells) were associated with haematopoietic/endothelial differentiation, as revealed by Gene Ontology (GO) terms and GSEA analyses (Fig. 4b, examples of genes in Fig. 4c). In contrast, the 998 genes upregulated in $\mathrm{Scl}^{-/-}$ cells were associated with mesoderm, cardiac and paraxial lineage development (Fig. 4b, examples of genes in Fig. 4c). Interestingly, genes encoding transcriptional repressors were also activated in WT cells (Fig. 4b, c), for example SCL's partner ETO2 (CBFA2T3) 36 .

SCL ChIP-seq from day 3.5 WT FLK1 ${ }^{+}$cells revealed 9836 SCL-bound loci. GO terms associated with the genes nearest to the peaks were related to haematopoiesis, vasculature and cardiac development (Fig. 4d). Combining RNA- and ChIP-seq datasets revealed 778 differentially expressed, SCL-bound loci (hereafter referred to as SCL direct DEGs, Fig. 4e, Supplementary Data 1). 
a

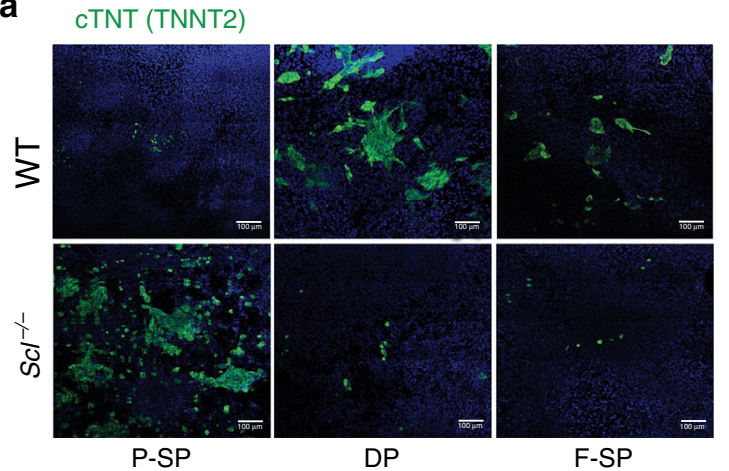

b
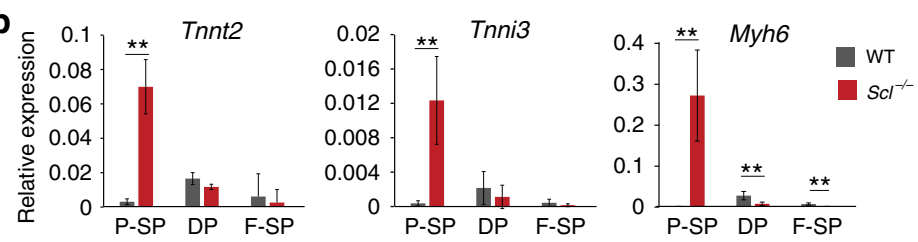

C
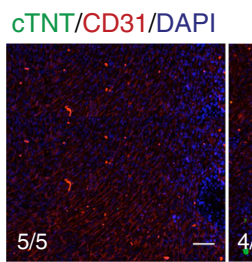

WT

e d Alcian blue

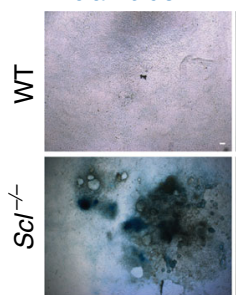

P-SP

g

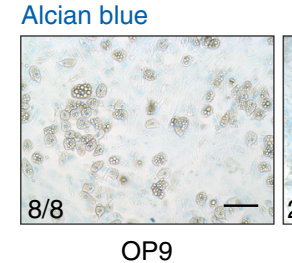

i

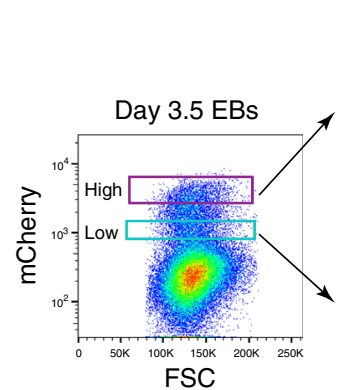

Re-aggregation assay day $3.5+24 \mathrm{hrs}$

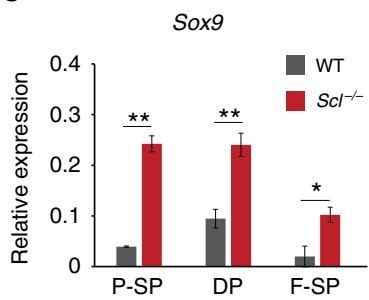

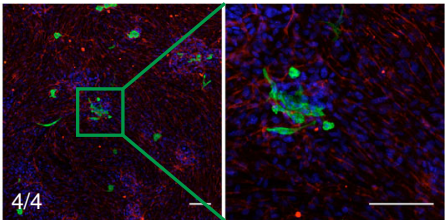

$\mathrm{Scl}^{-/-}$ f

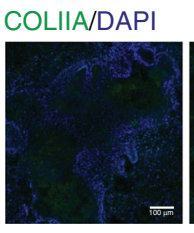

WT

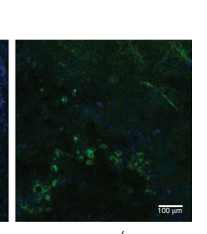

$\mathrm{SCl}^{-/-}$
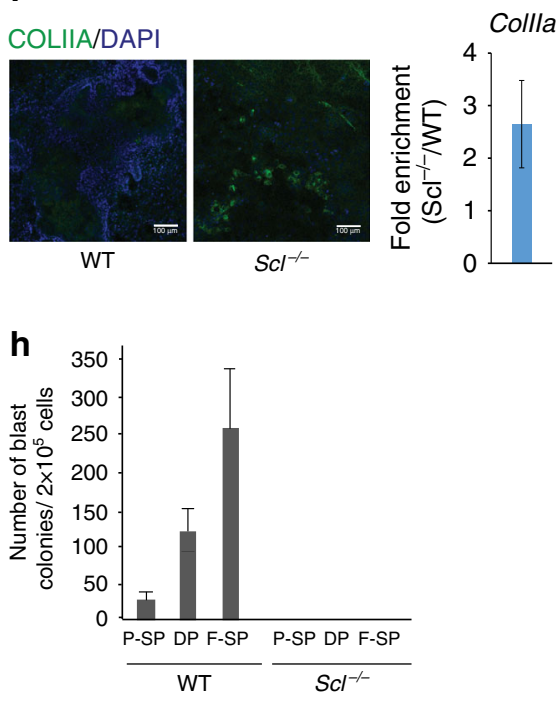

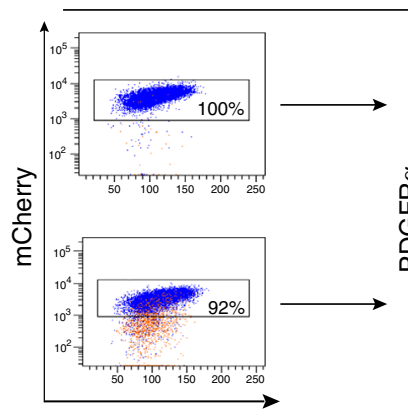

FSC

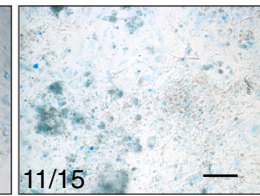

$\mathrm{SCl}^{+1-}$

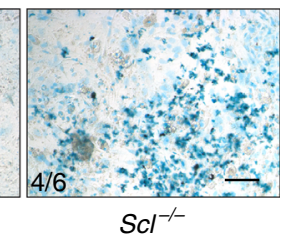

Cardiac assay

j
mCherry high
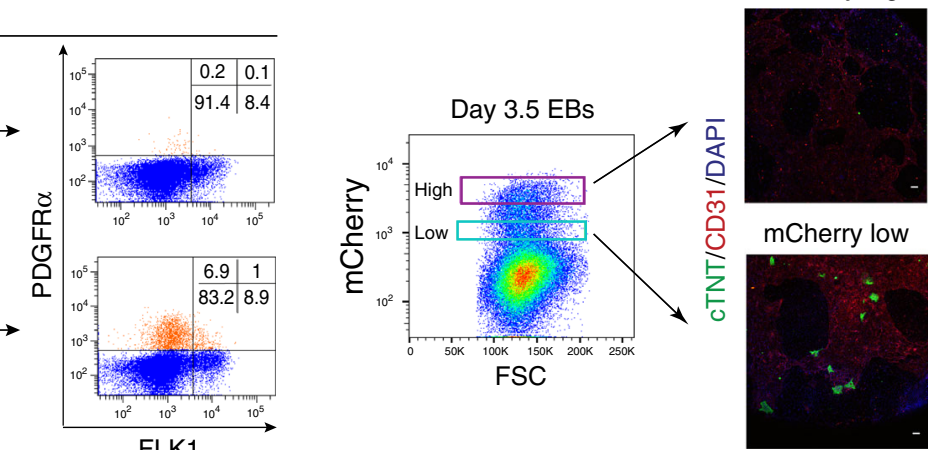

$514 / 778$ genes were more highly expressed in WT cells and related to haematopoiesis and vasculogenesis (Runx1/Fli1, Fig. 4e, f.) 264/778 genes showed increased expression in $\mathrm{Scl}^{-/}$cells and were related to mesoderm, cardiac (Gata6/Mesp1) and paraxial lineages (Tbx6) (Fig. 4e, f).

We next examined the 100 DEG-associated peaks showing the strongest SCL binding (greatest number of mapped reads from ChIP-seq data) (Fig. 4g, Supplementary Data 2). Remarkably, 97 of these peaks were attributed to genes normally activated by SCL. Whilst 22 peaks were associated to haematopoiesis-related genes and 10 to endothelium-related genes, 27 were associated with 4 genes encoding blood-related transcriptional repressors: Zfpm 1 and Gse1 (Fig. 4f), Eto2 and Runx1t1 (Eto). In addition to these 4 genes, another 7 transcriptional repressors, either expressed in blood cells (Zfpm2/Gfi1/Gfilb/Ikzf1/Izkf2) or members of the general repressive complex ncPRC1 (Rybp and its partner Pcgf5) were SCL direct targets (Supplementary Data 1). Of note, the number of SCL peaks was higher in loci normally activated (Runx1/Fli1/Zfpm1/Gse1) than on those normally repressed (Gata6/Mesp1/Tbx6) (Fig. 4f; Wilcoxon rank-sum test confirmed the difference in peak distribution between all 514 downregulated and 264 upregulated direct DEGs at $p$ value $\left.5.8 \times 10^{-08}\right)$. This 
Fig. $3 \mathrm{Scl}$-null cells acquire cardiac and paraxial potentials. a-c Cardiac assays. a Day $3.5 \mathrm{WT}$ and Scl\%- P-SP, DP, and F-SP populations were replated in cardiac condition for 7 days and cTNT (cardiac troponin) expression monitored by immunofluorescence (IF); scale bar, $100 \mu \mathrm{m}$. b RT-qPCR analysis of cardiac gene expression (Tnnt2, Tnni3 and Myh6) relative to Gapdh in cultures shown in $\mathbf{a} ; n=3-5$. c Day E9.5 WT and Scl/- mouse yolk sacs replated in cardiac assay for 7 days. IF reveals cardiomyocytes (cTNT, green), endothelium (CD31, red) and nuclei (DAPI, blue). d-g Chondrogenic assays. d Day 3.5 WT and $\mathrm{Sc} \%$ - P-SP, DP and F-SP populations were replated in chondrogenic condition for 21 days. Alcian blue staining reveals glycosaminoglycan clusters; e RT-qPCR analysis of Sox 9 expression relative to Gapdh in cultures shown in $\mathbf{d}, n=2$. $\mathbf{f}$ Collagen Ila (Collla) expression following culture of day 3.5 WT and $\mathrm{Scl}^{\%}$ - EB cells in chondrogenic condition (left, IF: COLIIA green, DAPI blue; right, RT-qPCR analysis) $n=2$. $\mathbf{g}$ Alcian blue staining of day 18 chondrogenic cultures from day E9.5 WT, $\mathrm{Scl}^{+/-}$and $\mathrm{Scl}^{-}$- mouse yolk sacs. OP9, no yolk sac cells. c, $\mathbf{g}$ Number of embryos presenting the phenotype shown is indicated for each genotype. $\mathbf{h}$ Blast colony assay showing number of endothelial/haematopoietic colonies obtained from day $3.5 \mathrm{WT}$ and Scl/- purified mesodermal populations (P-SP, DP, F-SP); $n=3$. i Left: day $3.5 \mathrm{Scl}$ :mCherry WT cells were FACS-sorted according to the level of mCherry (and therefore SCL) expression into low and high fractions. Right: mCherry high and mCherrylow cells were re-aggregated for 24 h, and mCherry (left) and FLK1/PDGFR (right) expression re-assessed. Note that only the day 3.5 mCherrylow fraction produced a PDFGR $\alpha^{+}$population (bottom right panel, orange events). At day $3.5+$ $24 \mathrm{~h}$, the majority of the PDGFR $\alpha^{+}$cells have lost mCherry expression (bottom left panel, orange events). j Day 3.5 Scl:mCherryhigh and Scl:mCherrylow FACS-sorted cells were replated in cardiac assay. IF reveals cardiomyocytes (cTNT, green), endothelium (CD31, red) and nuclei (DAPI, blue). Mean \pm SD is shown (b), (e), (f), (h); student's t-test, ${ }^{\star} p<0.05,{ }^{\star \star} p<0.01$. Scale bars, $100 \mu \mathrm{m}$. See also Supplementary Fig. 3

suggests mechanistic differences in SCL-mediated transcriptional activation versus repression.

In summary, SCL normally activates a blood/endothelial programme in $\mathrm{FLK}^{+}$cells and represses cardiac and paraxial programmes. Unexpectedly, SCL strongly binds to and activates expression of genes encoding transcriptional repressors. This suggests that SCL may suppress cardiac/paraxial programmes in blood-fated cells through transcriptional activation of repressors.

SCL controls levels of histone marks linked to repression. To further understand SCL-driven mechanisms of transcriptional regulation, we surveyed histone marks associated with activated and repressed genes (H3K27ac/H3K4me3 and $\mathrm{H} 3 \mathrm{~K} 27 \mathrm{me} 3 /$ H2AK119ub, respectively) by quantitative ChIP-seq (ChIP-Rx ${ }^{37}$ ) in mCherry ${ }^{+}$cells isolated from $S c l: m$ Cherry and $S c l^{\Delta / \Delta}: m$ Cherry day 4 EB cells. H3K27ac, the only mark detected at SCL genomic binding sites, was analysed at all 9836 SCL ChIP peaks (Fig. 5a) and on SCL peaks associated to SCL's 778 direct DEGs (Fig. 5b). As all these histone modifications mark promoter regions, we examined their distribution at transcriptional start sites (TSSs) of SCL-bound 5512 loci, whole genome TSSs and TSSs of SCL's 778 direct DEGs (Fig. 5c-f).

$\mathrm{H} 3 \mathrm{~K} 27 \mathrm{ac}$ was higher at SCL 9836 peaks in WT cells (Scl: $m$ Cherry) than in Scl-null cells $\left(S c l^{\Delta / \Delta}: m\right.$ Cherry) (Fig. 5a), consistent with SCL's ability to recruit histone acetyltransferase $\mathrm{P} 300^{38}$. H3K27ac at SCL peaks located in SCL direct DEG genomic loci was higher in the 514 activated genes compared to the 264 repressed genes (Fig. 5b, top) in an SCL-dependent manner (Fig. 5b, bottom). In contrast, H3K27ac and H3K4me3 levels at TSSs of the 5512 loci bound by SCL (of which only 422 are bound by SCL at TSSs) and TSSs genome-wide were SCLindependent (Fig. 5c). As expected, the level of these two histone marks was higher at TSSs of the 514 activated genes compared to the 264 repressed genes and SCL-independent (Fig. 5d). Extending these observations, we noticed a broad and punctuate $\mathrm{H} 3 \mathrm{~K} 27 \mathrm{ac}$ pattern at activated gene loci, not just restricted to SCL peaks and fully SCL-dependent (Fli1/Mafb, Supplementary Fig. 4a). SCL-independent H3K4me3 distribution at TSSs was visualised at both activated (Fli1/Mafb) and repressed (Gata6/Irx3) genes (Supplementary Fig. 4a, b). In summary, levels of H3K27 acetylation are higher and SCL-dependent at SCL's peaks associated to genes normally activated. At TSSs, both $\mathrm{H} 3 \mathrm{~K} 27 \mathrm{ac}$ and $\mathrm{H} 3 \mathrm{~K} 4 \mathrm{me} 3$ marks are more prominent at genes normally activated and are SCL-independent.

We next studied histone marks associated with repression, H3K27me3 and H2AK119ub. In contrast to H3K27ac and H3K4me3, we observed a striking, global SCL-dependent reduction of these marks, at TSSs of the 5512 SCL-bound loci and TSSs genome-wide (Fig. 5e). This reduction was confirmed by western blot (Fig. 5g, Supplementary Fig. 8a). Furthermore, whereas SCL-dependent levels of H3K27me3 were just confined to $\sim 2.5 \mathrm{~kb}$ around TSSs genome-wide, SCL-dependent levels of H2AK119ub extended for large domains (at least $100 \mathrm{~kb}$ ) either side of the TSSs (Fig. 5h). Focussing on the 778 SCL direct DEGs, H3K27me3 levels were higher at TSSs of repressed, rather than activated, genes (Fig. 5f, top), and showed SCL-dependence at repressed and, to a lesser extent, activated genes (Fig. 5f, bottom; Gata6/Irx3/Mafb, Supplementary Fig. 4). Surprisingly, the level of the H2AK119ub mark did not vary between TSSs of genes repressed and activated by SCL (Fig. 5f, top), and, in both cases, was SCL-dependent (Fig. 5f, bottom, Supplementary Fig. 4).

Taken together, these data show that SCL mediates H3K27 acetylation specifically at SCL-bound cis-regulatory elements of genes it normally activates. SCL also regulates the level of repression-associated histone marks, H3K27me3 and H2AK119ub, not only at TSSs of genes it normally represses but also at some (H3K27me3) or all (H2AK119ub) genes it activates. This suggests that inappropriate gene activation may be restrained by SCL-mediated repressive environment. Regulation of repression, as surveyed by histone modifications, constitutes an important facet of SCL function at the onset of blood specification.

ETO2, RYBP and SCL are functionally linked. To investigate SCL-regulated active repression of gene expression in mesoderm patterning, we studied two transcriptional repressors and direct SCL target genes in day $3.5 \mathrm{FLK}^{+}{ }^{+}$cells, ETO2 and RYBP. ETO2 is a known SCL partner that represses premature megakaryocytic and erythroid gene activation later in development ${ }^{36,39,40}$. RYBP, member of non-canonical PRC1 (ncPRC1) complexes, modulates H2AK119 ubiquitination levels through stabilisation of RING1B recruitment and enhancement of its enzymatic activity ${ }^{41-43}$. Given the role of PcG complexes in development and the changes in ubiquitination levels observed in $\mathrm{Scl}^{-/}$cells, we reasoned that RYBP may mediate some of SCL-regulated repression mechanisms.

The Eto2 locus was bound by SCL at conserved cis-elements associated with open chromatin (ATAC-seq) and containing DNA-binding motifs associated to SCL binding (Fig. 6a, Supplementary Fig. 5a). Eto 2 mRNA expression was initiated at day 3.5, increased throughout EB differentiation, thus mirroring Scl's expression (Figs. 1a, 6b) and was abolished in absence of SCL (Fig. 6b). Finally, ETO2 was immunoprecipitated from EB cells with SCL and partners E2A and LMO2 (Fig. 6c, Supplementary Fig. 9a).

Day 4 ETO2 ChIP-seq analysis showed co-localisation with SCL at 1949 peaks, which represent $20 \%$ of all SCL peaks and 
a RNA-seq

$\mathrm{Scl}^{-1-}$ versus WT: 2036 genes Ilog ${ }_{2} \mathrm{FCl}>0.48 ;$ pAdjvalue $<0.05$

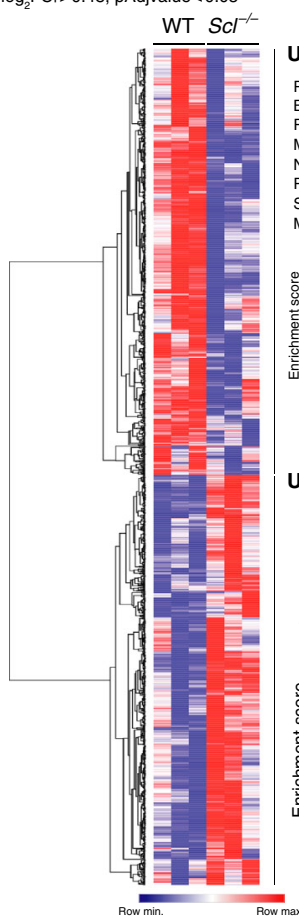

UP in WT cells: $\mathbf{1 0 3 8}$ genes

Pos. regulation of transcription, RNA Pol II Pon ( $p$ Value) (1.40 10 $\begin{array}{ll}\text { Regulation of erythrocyte differentiation } & 1.0710^{-6} \\ & 1.45\end{array}$ Wyelid cell diterentation $1.3310^{-5}$ Reg. regula don or ranscription, RNA Poll promotor $50310^{-5}$ $\begin{array}{ll} & 8.7010^{-5} \\ & 39210^{-3}\end{array}$ $\begin{array}{ll} & 3.9210^{-3} \\ & 1.4010^{-2}\end{array}$

Stem Cell (nematopoietic) ETO2 targets
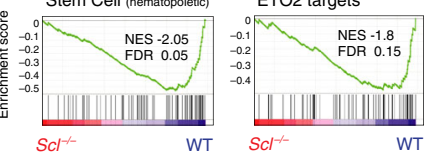

\section{$\mathrm{UP}$ in $\mathrm{Scl}^{-/}$cells: 998 genes}

Gastrulation

Mesoderm developmen

$1.0810^{-5}$

egative regulation of certcel a

Muscle tissue developmen

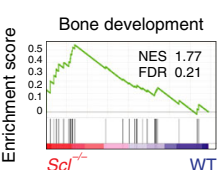

e

RNA-seq

WT versus $\mathrm{SCl}^{-1-}$ 2036 DEGs

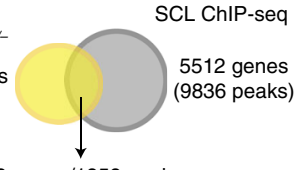

778 genes $/ 1858$ peaks

GO biological processes

Upregulated in WT cells- 1356 peaks/514 genes

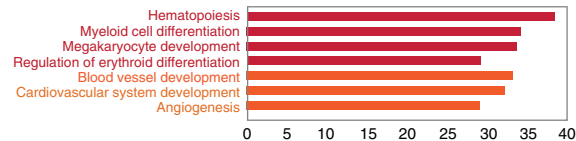

Upregulated in $\mathrm{SCl}^{-/}$cells -502 peaks/264 genes

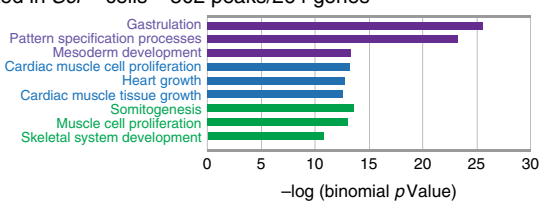

g

First 100 strongest SCL ChIP-seq peaks asociated to DEGs

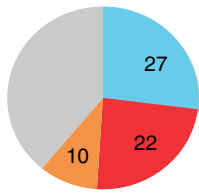

Repressors (4)

Hematopoiesis-related (12)

Endothelial-related (5)

Other (22)

f

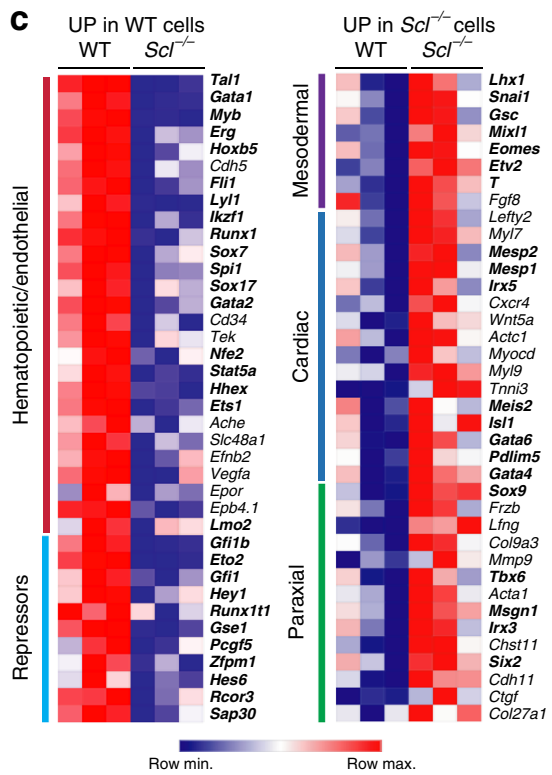

d SCL ChIP-seq - 9836 peaks - GO biological processes

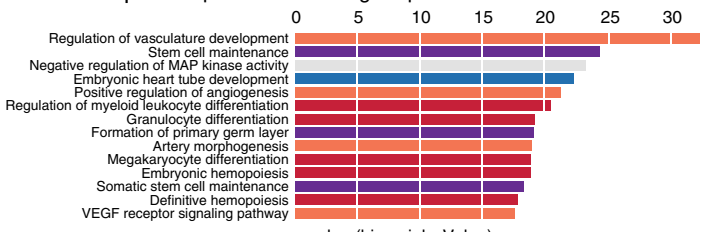

$-\log ($ binomial $p$ Value)

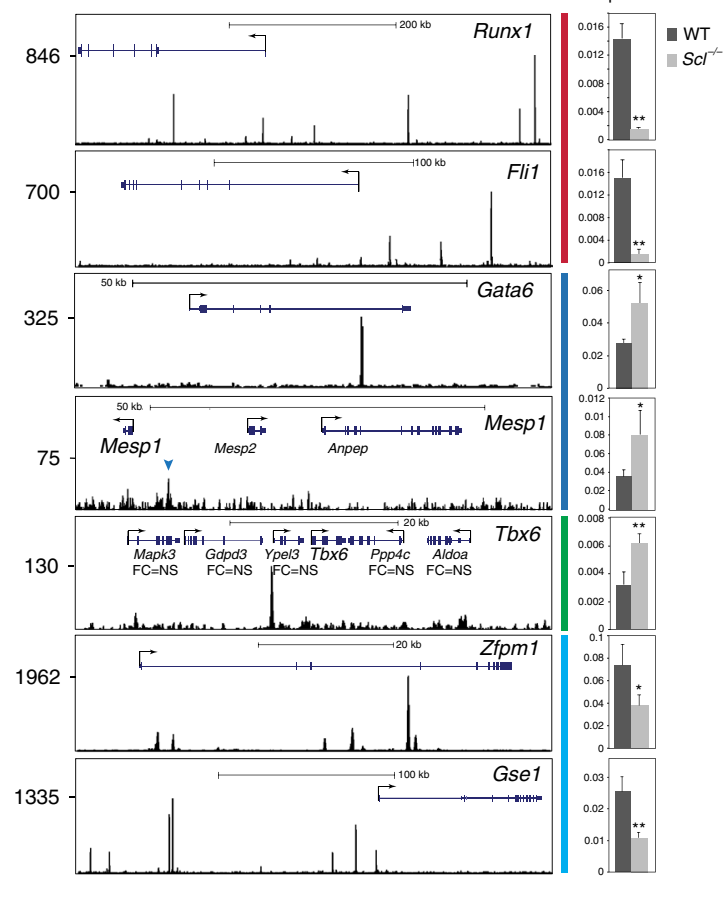

Fig. $4 \mathrm{SCL}$ controls distinct gene regulatory networks in day $3.5 \mathrm{FLK}^{+}$cells. a Hierarchical clustering of RNA-seq data from day $3.5 \mathrm{WT}$ and $\mathrm{Scl}{ }^{1-} \mathrm{FLK} 1^{+} \mathrm{EB}$ cells. b Gene ontology (GO) processes associated to differentially expressed genes (DEGs) (PANTHER and GSEA analyses). c Heatmap showing selected DEGs associated to $\mathrm{GO}$ processes identified in $\mathbf{b}$. In bold, transcriptional regulators. $\mathbf{d}$ The top more significant $\mathrm{GO}$ biological processes associated to SCLbound loci (GREAT analysis). e Integration of SCL ChIP-seq and RNA-seq data reveals $778 \mathrm{SCL}$ direct differentially expressed target genes. Below, GO terms attributed to DEG-associated peaks (GREAT analysis). $\mathbf{f}$ Left, SCL ChIP-seq tracks of selected direct DEGs; FC $=N S$, fold-change in expression in $\mathrm{Scl}^{\text {/- }}$ cells is not significant (RNA-seq data). Tbx6 locus: the SCL peak was attributed to Tbx6, the closet DEG. Right, RT-qPCR gene expression analysis relative to Gapdh from WT and Scl/- day $3.5 \mathrm{FLK} 1^{+}$cells. $n=3$, mean $\pm \mathrm{SD}$; student's $t$-test, ${ }^{\star} p<0.05,{ }^{\star \star} p<0.01$. Colour code, same as in $\mathbf{c}$. $\mathbf{g}$ Biological functions attributed to the 100 strongest DEG-associated SCL ChIP-seq peaks. In brackets, numbers of genes in each category. See also Supplementary Data 1,2 


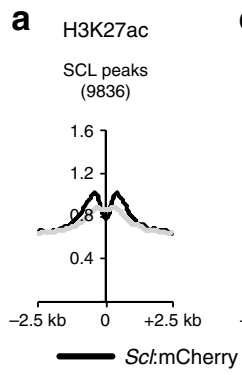

C

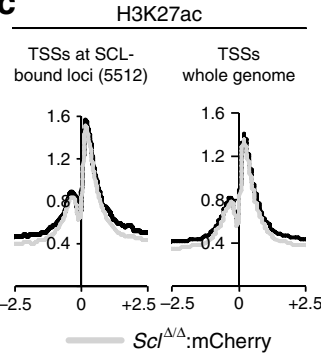

b H3K27ac (SCL peaks)

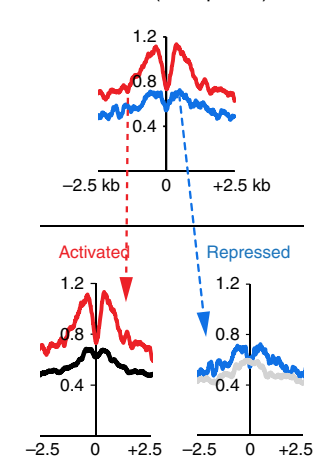

d H3K27ac (TSSs)
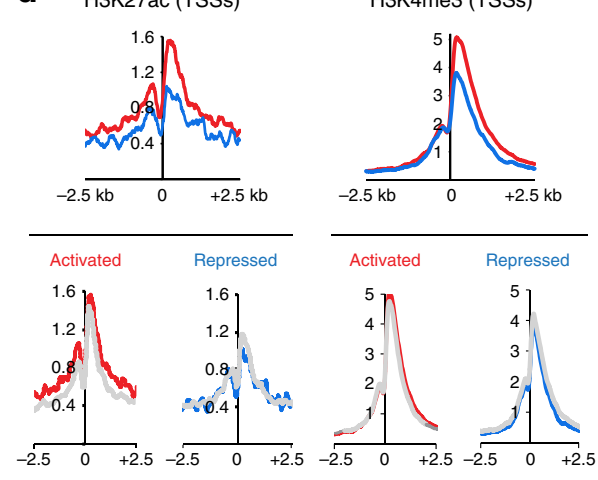

H3K4me3 (TSSs)

$\left.\begin{array}{l}514 \text { genes activated by SCL } \\ 264 \text { genes repressed by SCL }\end{array}\right]$ Scl:mCherry

g

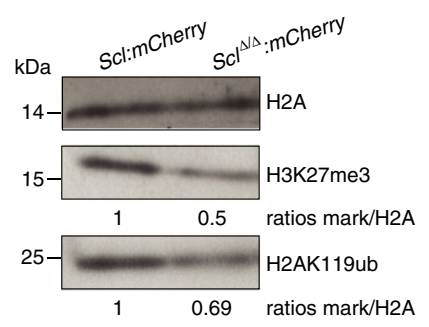

$1 \quad 0.69$ ratios mark/H2A
$S c l^{\Delta \Delta}:$ mCherry

h

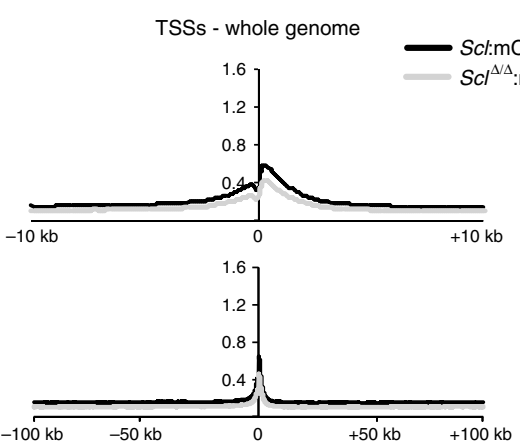

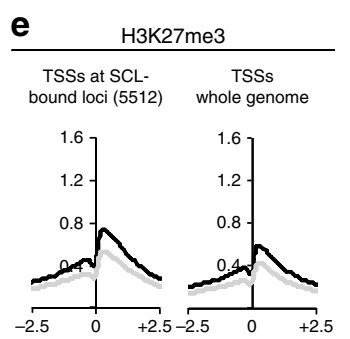
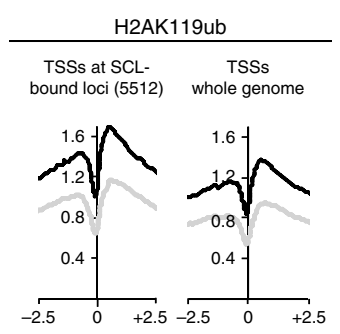

f
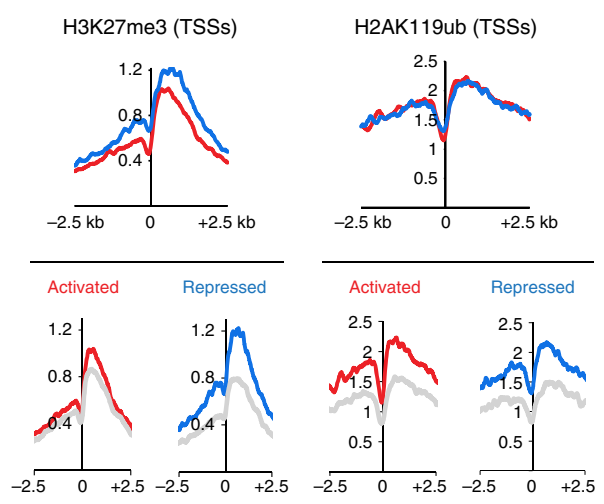

H3K27me3

H2AK119ub

TSSs - whole genome

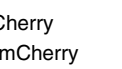

Fig. 5 SCL loss-of-function affects the epigenetic landscape of blood-fated progenitors. a, c, e Distribution plots of normalised histone mark ChIP-seq signals in $\mathrm{mCherry}+$ cells purified from Scl:mCherry and Sc/4/4:mCherry day 4 EBs. Signals are sorted on SCL ChIP-seq peaks (a H3K27ac only), TSSs of SCLbound 5512 genes and TSSs across the whole genome, $\pm 2.5 \mathrm{~kb}$, (c activation associated-marks H3K27ac and H3K4me3; e repression associated-marks H3K27me3 and H2AK119ub). b, d, f Distribution plots of normalised histone mark ChIP-seq signals in mCherry ${ }^{+}$cells purified from Scl:mCherry and Scl${ }^{\Delta / \Delta}$ : mCherry day 4 EBs on SCL direct DEGs (514 activated genes (red) and 264 repressed genes (blue)). Signals are sorted on SCL ChIP-seq peaks associated to SCL direct DEGs (b H3K27ac only) and TSSs of SCL direct DEGs, $\pm 2.5 \mathrm{~kb}$ (d, activation associated-marks; $\mathbf{f}$ repression associated-marks). Top, Scl: mCherry EB cells; bottom, Scl:mCherry and $S c{ }^{\Delta / \Delta}$ :mCherry EB cells. $\mathbf{g}$ Western blot analysis of H3K27me3 and H2AK119ub levels in mCherry ${ }^{+}$cells purified

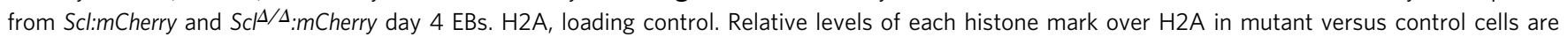
indicated. $n=2$. h Distribution plots of normalised H3K27me3 and H2AK119ub ChIP-seq signals in mCherry ${ }^{+}$cells purified from Scl:mCherry and Scl ${ }^{/ 4} \Delta$ : $m$ Cherry day 4 EBs. Signals are sorted on TSSs across the whole genome; top, \pm 10 kb, bottom, $\pm 100 \mathrm{~kb}$. See also Supplementary Figs. 4,8

$60 \%$ of all ETO2 peaks (Fig. 6d, Supplementary Fig. 6a). The biological processes related to the genes associated to these 1949 peaks were enriched for blood, vascular, cardiac and muscle development (Supplementary Fig. 6b). We then considered the 1725 gene loci co-occupied by SCL and ETO2. These corresponded to $31 \%$ of SCL-bound genes (1725/5512) and $79 \%$ of ETO2-bound genes (1725/2186) (Fig. 6e). These genes contained 352 out of SCL's 778 direct DEGs (45\%). The strength of SCL and ETO2 binding across these 352 DEGs was the same for both proteins: higher in the genes activated by SCL vs. those repressed (Supplementary Fig. 6c). Therefore, SCL and ETO2 often colocalise on activated and repressed genes and most likely cooperate in multi-protein complexes.
Similarly, SCL binding was detected at the loci encoding Rybp and its partner Pcgf5, in areas associated with open chromatin and SCL-binding DNA motifs (Fig. 6f, Supplementary Fig. 5b). Strikingly, expression of Rybp and Pcgf5 was significantly downregulated in days 3.5/4 Scl-1- EB cells (Fig. 6g), corresponding to the narrow time-window of transcriptional copriming of blood/cardiac/paraxial lineages and developmental plasticity of F-SP cells (Figs. 1d, 2c). None of the other members of PRC1/PRC2 complexes we examined, including enzymes responsible for deposition of PcG-associated histone marks (Ring1a/1b, Ezh1/2), or members of the KAT and TrxG activating complexes, were direct targets of SCL (Fig. 6f, g, Supplementary Fig. 7), highlighting the unique relationship between SCL and 
1
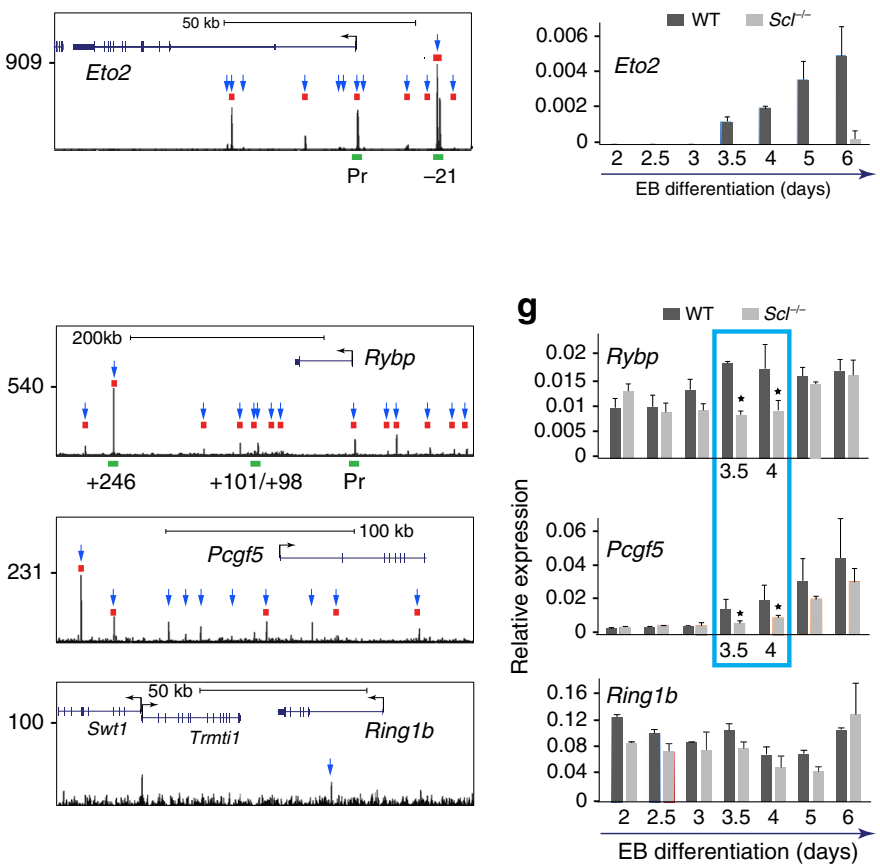

C

h

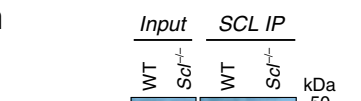

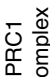
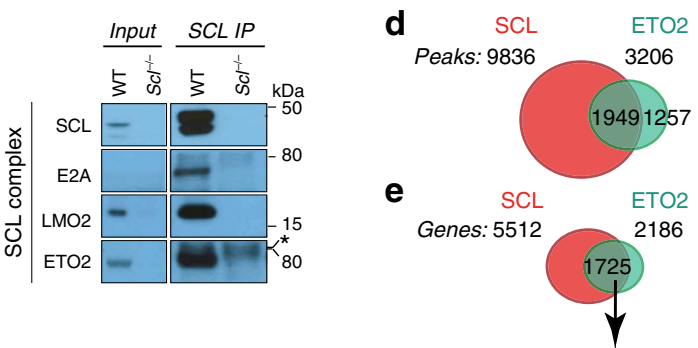

352/778 SCL direct DEGs

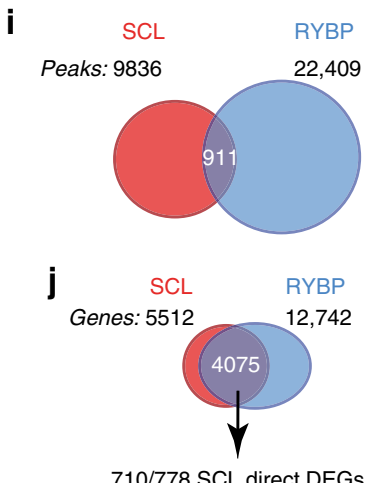

710/778 SCL direct DEGs
778 SCL direct DEGs

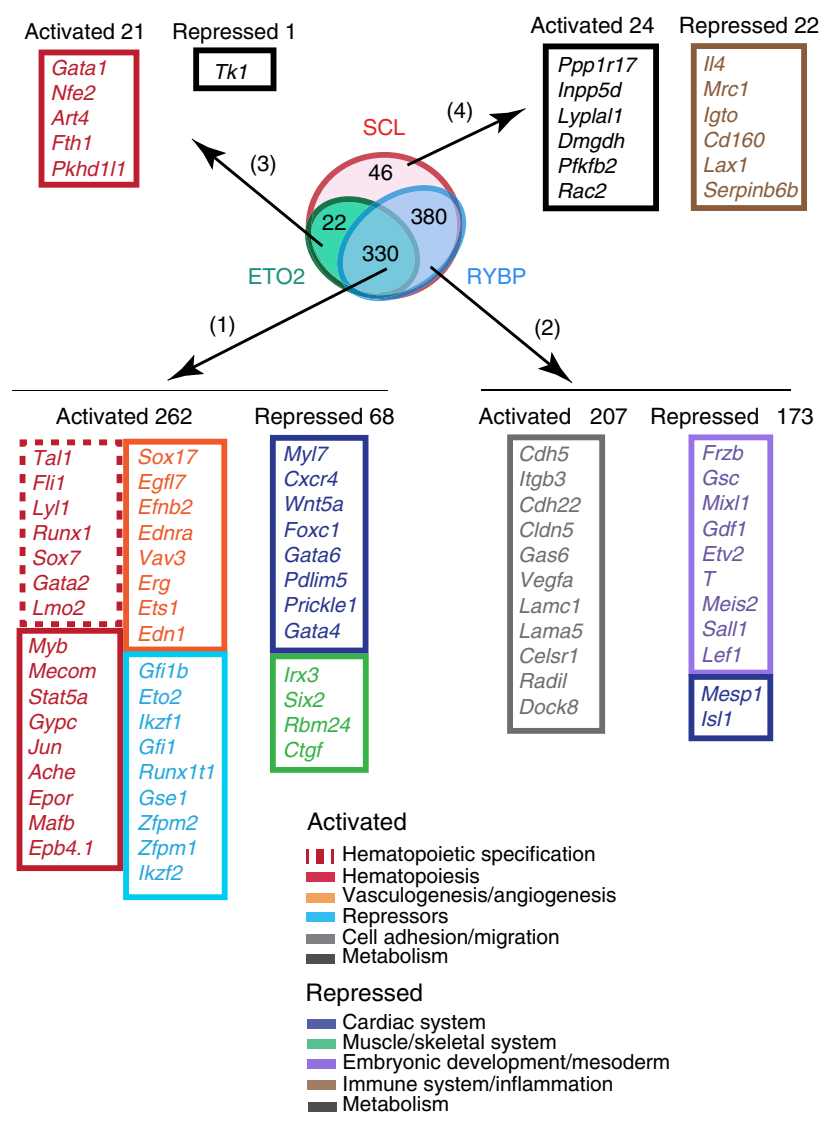

I (1) SCL/ETO2/RYBP
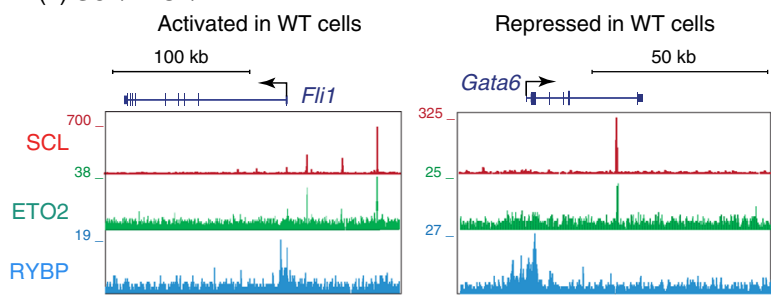

(2) SCL/RYBP
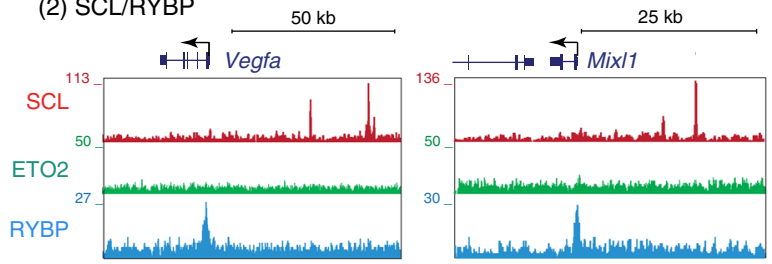

(3) SCL/ETO2
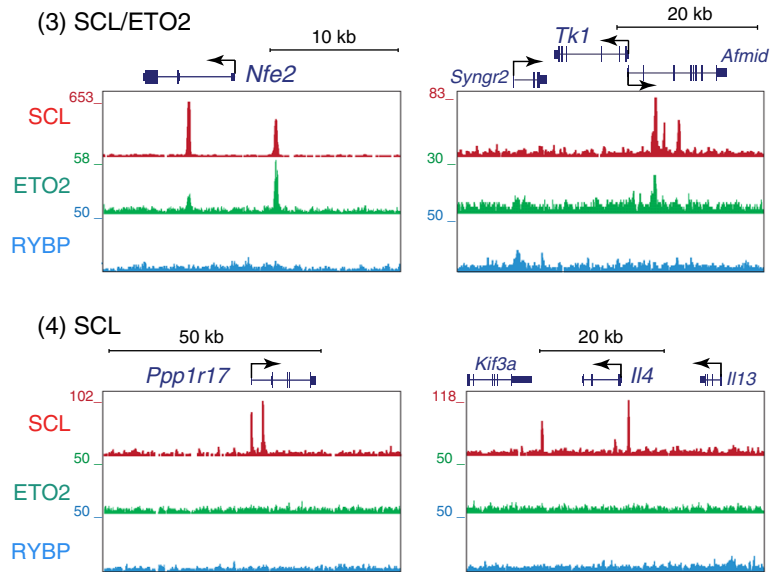
Fig. 6 Genome-wide binding of SCL, ETO2 and RYBP in FLK1+ cells. a SCL ChIP-seq track of Eto2 locus in day 3.5 FLK1+ EB cells. Blue arrows, SCL peaks associated to Eto2; red rectangles, ATAC peaks; green rectangles, SCL-bound cis-elements further detailed in Supplementary Fig. 5. b RT-qPCR analyses of Eto2 mRNA expression from WT and Scl/- EB differentiation kinetics (day 2-day 6) relative to Gapdh. $n=3-5$, mean \pm SD; student's $t$-test ${ }^{*} p<0.05$. c Western blot analysis of day 4.5 WT EB nuclear extracts immunoprecipitated (IP) with anti-SCL antibodies. Members of SCL complex are detected as indicated. $n=3$. d Overlap between SCL and ETO2 ChIP-seq peaks. e Overlap between SCL-bound and ETO2-bound genes. 352 of these are SCL direct DEGs. f SCL ChIP-seq track of Rybp, Pcgf5 and Ring $1 b$ loci in day $3.5 \mathrm{FLK1} 1^{+}$EB cells. Blue arrows, SCL peaks associated to the genes; red rectangles, ATAC peaks; green rectangles, SCL-bound cis-elements further detailed in Supplementary Fig. 5. g RT-qPCR analyses of Rybp, Pcgf5 and Ring $1 b$ mRNA expression from WT and Scl- - EB differentiation kinetics (day 2-day 6) relative to Gapdh. $n=3-5$, mean \pm SD; student's $t$-test ${ }^{*} p<0.05$. $\mathbf{h}$ Western blot analysis of day 4.5 WT EB nuclear extracts immunoprecipitated (IP) with anti-SCL antibodies (top), -RYBP (bottom, left) and -RING1B (bottom, right) antibodies.

Members of PRC1 complex (RING1B, RYBP) and SCL complex (LMO2, ETO2) are detected as indicated. Asterisk (*) indicates heavy or light lgG chain. White arrow indicates SCL band in RING1B IP. i Overlap between SCL and RYBP ChIP-seq peaks. $\mathbf{j}$ Overlap between SCL-bound and RYBP-bound genes. Seven hundred and ten of these are SCL direct DEGs. k Overlap between SCL-bound, ETO2-bound, and RYBP-bound 778 SCL direct DEGs. Number and representative examples of SCL direct target genes in the four categories defined by SCL, ETO2, and RYBP binding are shown. I UCSC tracks showing SCL, ETO2 and RYBP binding on examples of activated and repressed SCL direct DEGs in the four categories defined by SCL, ETO2, and RYBP binding. See also Supplementary Figs. 4-6 and 9, Supplementary Data 3

RYBP/PCGF5. Finally, in contrast to the Eto2 locus, binding of SCL to Rybp and Pcgf5 loci was not seen in maturing blood cells (foetal liver pro-erythroblasts) $^{44}$ (Supplementary Fig. 5a, b), suggesting specific requirements for these two repressors during early blood specification processes.

Immunoprecipitation (IP) of $\mathrm{EB}$ nuclear extracts with either RYBP or RING1B antibodies co-purified the SCL/E2A/LMO2 complex (Fig. 6h, bottom, Supplementary Fig. 9b, c). Reciprocal IP using SCL antibodies recovered RING1B but not RYBP (Fig. 6h, top, Supplementary Fig. 9a), suggesting that only a small fraction of RING1B/RYBP is complexed with SCL. Indeed, SCL and RYBP binding co-localised at only 911 peaks by day $3.5 / 4$ ChIP-seq analyses, which represents $9 \%$ of SCL peaks and $4 \%$ of RYBP peaks (Fig. 6i, Supplementary Fig. 6d). Interestingly, GO analysis of the biological processes associated with the loci related to the 911 peaks showed enrichment for blood, cardiac and muscle development (Supplementary Fig. 6e). Finally, 4075 gene loci showed SCL and RYBP co-occupancy (where binding does not necessarily co-localise), corresponding to $73 \%$ of SCL-bound genes and $31 \%$ of RYBP-bound genes (Fig. 6j). These genes contained 710 out of 778 (91\%) SCL direct DEGs, suggesting coregulation by SCL and RYBP (Fig. 6j).

In conclusion, ETO2's expression entirely relies on SCL throughout EB differentiation and full expression of RYBP and PCGF5 requires SCL within a narrow developmental window. ETO2 and RYBP interact with SCL. When considering gene loci, ETO2 co-occupies nearly half and RYBP the majority of SCL direct DEGs.

Genome-wide interaction of SCL, ETO2 and RYBP with chromatin. To explore the shared and distinct gene sets regulated by SCL, ETO2 and RYBP, we examined the binding of these three regulators at SCL's 778 direct DEGs. This defined 4 gene categories:

(1) 330/778 gene loci (42\%) were co-occupied by SCL/ETO2/ RYBP (Fig. 6k, Supplementary Data 3). 262/330 genes were activated by SCL and required for blood (Scl/Fli1/Runx1/ Gata2) and endothelial (Sox17/Efnb2/Erg) development, haematopoiesis and erythropoiesis (Mafb/Gypc/Ache/Epor), and encoded transcriptional repressors (Gfilb/Eto2/Ikzf1/ Runx1t1) (Fig. 6k, 1). Sixty-eight genes were repressed by SCL and involved in differentiation of cardiac (Gata4/ Gata6/Wnt5a/Foxc1) and paraxial (Irx3/Six2/Ctgf) fates (Fig. 6k, 1).

(2) 380 genes (49\%) co-occupied by SCL/RYBP, but not ETO2, were equally activated and repressed (Fig. 6k, l). Activated genes were mainly associated with cell adhesion/migration
(Cdh5/Itgb3/Cdh22/Lamc1) and repressed genes with early developmental/mesoderm specification (Gsc/Mixl1/Etv2/T) (Fig. 6k, 1).

(3) 22 genes ( $3 \%$ ) co-bound by SCL/ETO2, but not RYBP, were mainly activated but functionally required at later stages of haematopoietic differentiation (Gata1/Nfe2) (Fig. 6k, 1).

(4) 46 genes (6\%) were only bound by SCL, equally activated or repressed and mainly involved in metabolism (activated genes) and inflammation (repressed genes) (Fig. 6k, l).

In conclusion, SCL and these repressors bind to overlapping and distinct functional categories of activated and repressed target genes.

Loss of Eto2 and Rybp phenocopies SCL-null cardiac phenotype. Given the aggregate molecular and biochemical data that SCL, ETO2 and RYBP could function in concert at the time of blood specification, we asked if loss of ETO2 or RYBP could phenocopy loss of SCL in developing EBs (Fig. 7a). We first knocked down expression of Eto2 and Rybp RNA and protein by siRNA, by $40-70 \%$, at day 3.5 (siEto 2 and siRybp, Fig. 7b, c, Supplementary Fig. 8b). The level of reduction of Rybp mimicked that seen in absence of SCL during the window of mesodermal lineage specification (Fig. 6g) and, strikingly, led to decreased levels of H2AK119ub similar to that observed in $S c l^{\Delta / \Delta}: m$ Cherry cells (Figs. 5g, 7c Supplementary Fig. 8c). Importantly, Eto2 and Rybp knock-down cells produced a 4-6-fold increase in cTNTpositive cells in cardiac assays, similar to that observed in absence of SCL (Fig. 7d, e). Similarly, induction of $R y b p$ deletion in $R y b p^{f l f l}:$ Cre-ERT2 $2^{45}$ EBs resulted in complete loss of Rybp expression (Fig. 7f) and expansion of cTNT-positive cardiac cells (Fig. 7g). Importantly, reduction of Eto2 and Rybp expression did not alter blood lineage specification assayed by blast colony assays (Fig. $7 \mathrm{~h}$ ).

To directly test the function of $\mathrm{H} 2 \mathrm{AK} 119 \mathrm{ub}$ in cardiac development, we treated EBs with PRC1 ubiquitin ligase inhibitor PRT4165 ${ }^{46}$. This achieved up to $84 \%$ decrease in ubiquitination levels (Fig. 7i, Supplementary Fig. 8d) and led to increased cardiac output, as judged by cTNT staining and Tnnt 2 mRNA expression (Fig. 7j), suggesting that H2AK119 ubiquitination mediates the cardiac phenotype observed from $\mathrm{Ry} b p$ knock-down and $S c l$-null cells.

Finally, we asked if reduction in $\mathrm{H} 3 \mathrm{~K} 27 \mathrm{me} 3$ could have a similar effect. We treated EBs with PRC2 inhibitor UNC1999 targeting EZH1/2 function ${ }^{47}$, to achieve near complete loss of H3K27me3 at day 3.5 (Fig. 7k, Supplementary Fig. 8e). Here, there was no increase in cardiac output assayed by cTNT staining and Tnnt2 mRNA expression (Fig. 7l). 
a
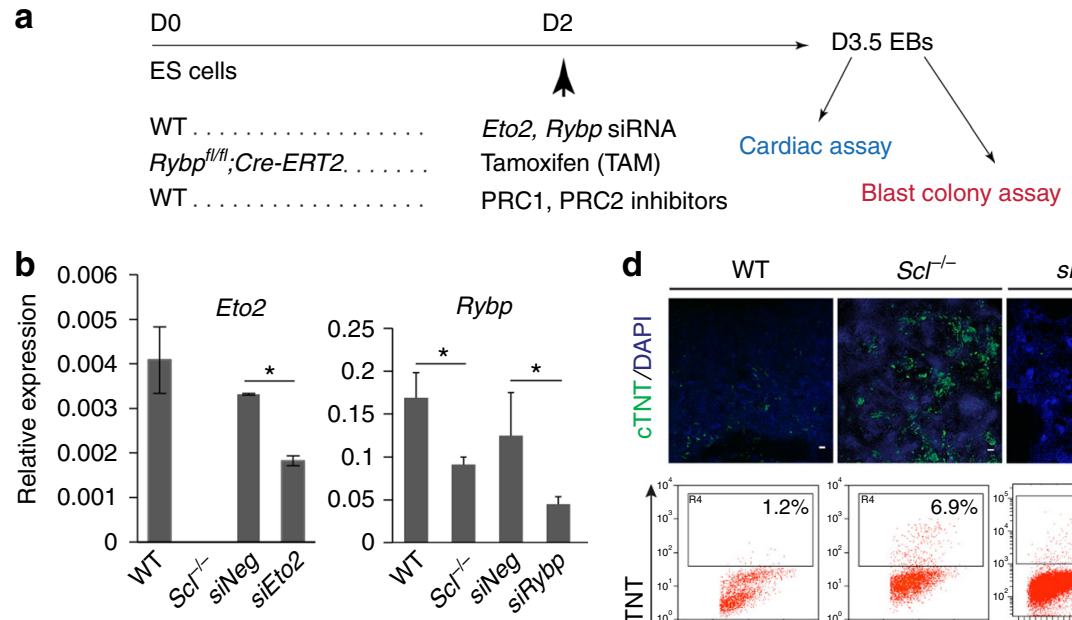

siNeg
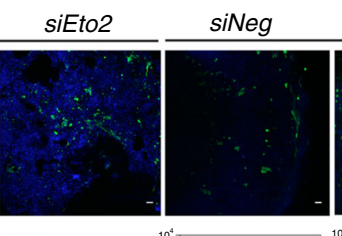

siRybp

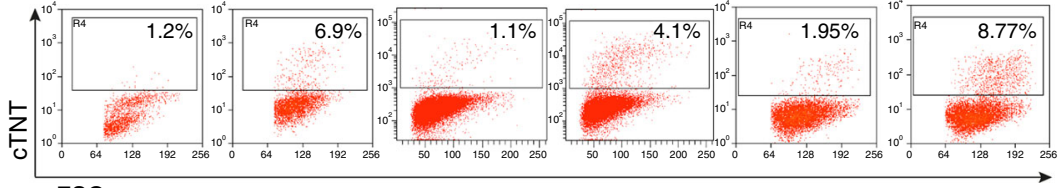

C
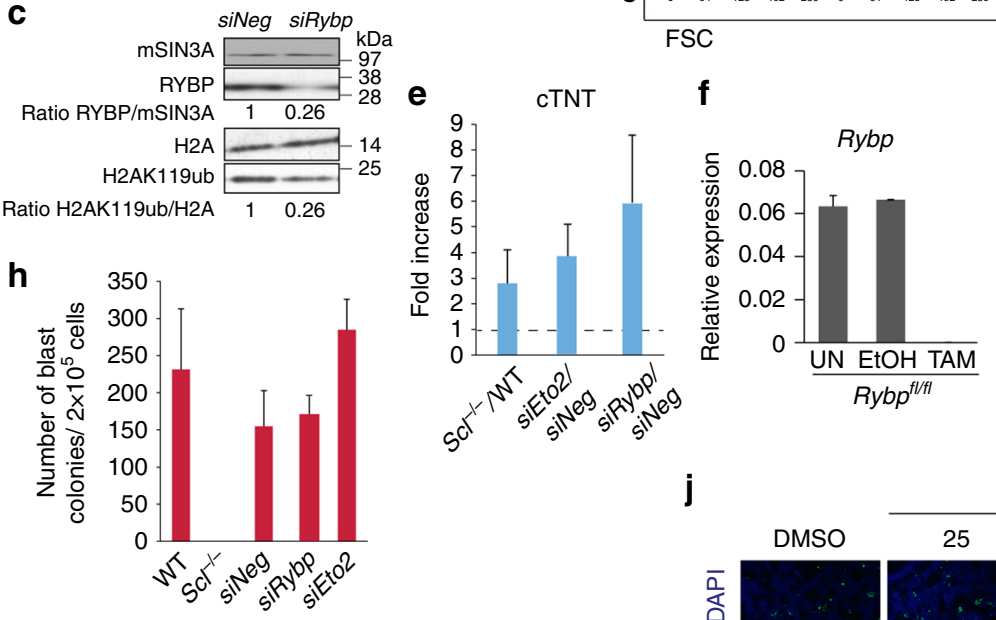

g

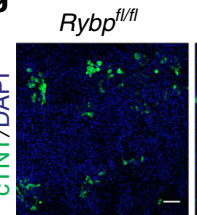

Untreated

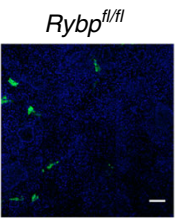

$\mathrm{EtOH}$
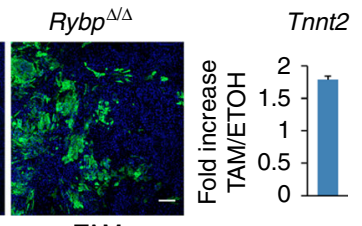

TAM
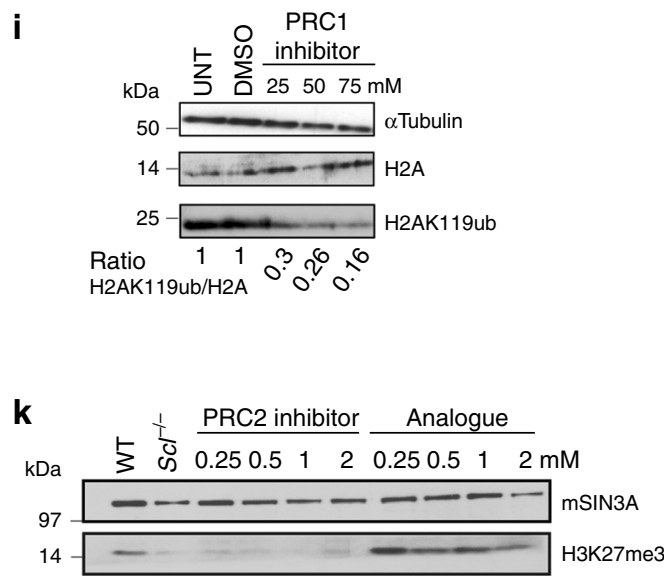

j
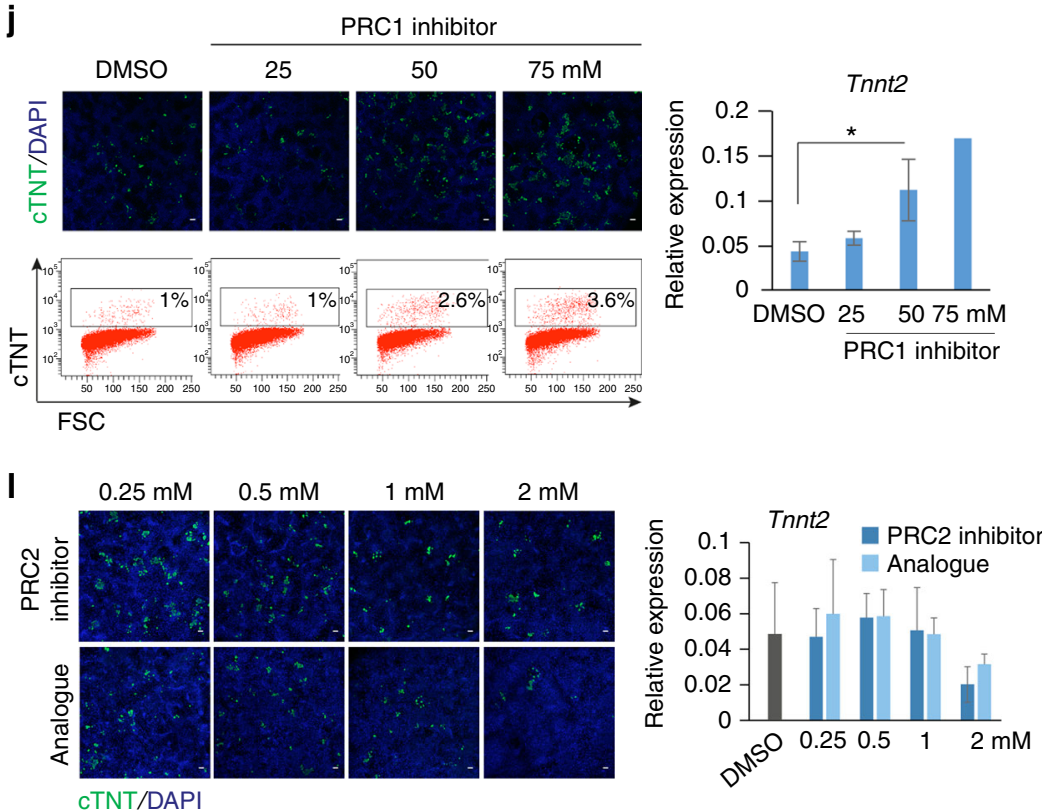

Altogether, these data suggest specific roles for ETO2 and RYBP and, by association, the PRC1 complex, most likely through H2AK119 ubiquitination, to suppress alternative fates in $\mathrm{FLK}^{+}$cells in collaboration with SCL.

\section{Discussion}

We have studied how lineage commitment is executed during development by focusing on how ES cell-derived $\mathrm{FLK} 1^{+}$mesodermal cells segregate into the blood lineage and suppress alternative cardiac and paraxial lineage programmes. We show that, at a narrowly defined time-point, a single TF, SCL, not only promotes haemopoiesis in $\mathrm{FLK}^{+}$cells, but concurrently suppresses mis-specification of these cells to alternative lineages (Fig. 8). A series of genome-wide molecular and biochemical studies demonstrates that SCL represses alternative gene expression in collaboration with ETO2 and the PRC1 complex at the precise time-point when multi-lineage transcriptional priming and cellular plasticity are detected. Whether this occurs in FLK1 ${ }^{+} \mathrm{SCL}^{+}$haematopoietic progenitors giving rise to primitive and/ 
Fig. 7 Rybp and Eto2 knock-down phenocopies Scl\%- cardiac phenotype. a Outline of functional assays. b-e siRNA-mediated Eto2 (siEto2) and Rybp (siRybp) knock-down in day 3.5 EBs. b qRT-PCR analysis of Eto2 and Rybp mRNA levels. Analysis from day $3.5 \mathrm{WT}$ and Scl/-EB cells is shown for comparison. siNeg, siRNA negative control; $n=4$. c Western blot analysis of RYBP and H2AK119ub levels. mSIN3A and H2A, loading controls; $n=2$. d, e Day 3.5 WT, Scl/-, siEto2-treated, siRybp-treated and siNeg-treated EB cells were plated in cardiac condition. CTNT expression was monitored at day 7 by IF (d, top) and intracellular FACS (d, bottom). Quantitation of FACS data from Scl\%-, siEto2- and siRybp-treated cultures is shown as Scl/- /WT, siEto2/siNeg and siRybp/siNeg ratios (e); $n=2$. Scale bars, $100 \mu \mathrm{m}$. $\mathbf{f}$ qRT-PCR analysis of Rybp expression in day 3.5 untreated (UN), tamoxifen- (TAM) and ethanol (EtOH)-treated CreERT2:Rybp ${ }^{f l / f l}$ EBs; $n=2$. g Day 3.5 untreated, EtOH-treated or TAM-treated CreERT2:Rybpfl/fl cells were plated in cardiac condition. cTNT expression was assessed at day 7 by IF (green, left) and qRT-PCR analysis (Tnnt2, shown as TAM/ETOH fold increase, right). Scale bar, $100 \mu \mathrm{m}$. $n=2$. h Day $3.5 \mathrm{WT}$, $\mathrm{Scl}^{\%}$ - siEto2-treated, siRybp-treated and siNeg-treated EB cells were plated in blast colony assay; $n=2$. i Western blot analysis of H2AK119ub in day $3.5 \mathrm{~EB}$ cells treated with increasing concentrations of PRC1 inhibitor (PRT4165). UNT, untreated; $\alpha$ Tubulin and H2A, loading controls, $n=2$. j PRC1 inhibitor or DMSO-treated EBs were plated in cardiac assay, and cTNT expression assessed at day 7 by IF (green, top), FACS (bottom) and qRT-PCR (Tnnt2, right); $n$ =3. $\mathbf{k}$ Western blot analysis of H3K27me3 in day 3.5 EB cells treated with increasing concentrations of PRC2 inhibitor or analogue. mSIN3A, loading control, $n=2$. I Day $3.5 \mathrm{~EB}$ cells treated with PRC2 inhibitor or analogue were plated in cardiac condition, and cTNT expression assessed at day 7 by IF (green, left) and qRT-PCR (Tnnt2, right). $n=2$. Scale bars, $100 \mu \mathrm{m}$. Mean \pm SD is shown in $\mathbf{b}, \mathbf{f}, \mathbf{h}, \mathbf{j}, \mathbf{l}$; mean of ratios of mutant samples versus controls \pm SD is shown in $\mathbf{e}, \mathbf{g}$; student's $t$-test, ${ }^{*} p<0.05$. See also Supplementary Fig. 8

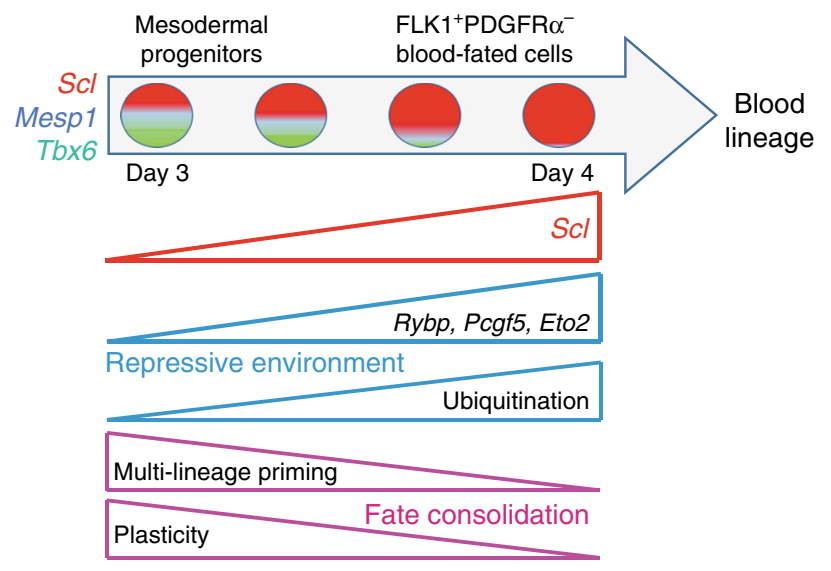

Fig. 8 Model of SCL's functions in blood lineage specification. Single mesodermal cells co-express blood ( $\mathrm{SCl}$ ), cardiac (Mesp1) and paraxial (Tbx6)-affiliated transcriptional regulators at low levels, establishing multilineage priming and cellular plasticity. As differentiation progresses, $\mathrm{Scl}$ levels increase in FLK1+PDGFR $\alpha^{-}$cells. SCL establishes a global repressive environment by activating potent transcriptional repressors (Rybp/Pcgf5/ Eto2) and ensuring genome-wide, high H2AK119Ub levels. This leads to decreased Mesp1 and Tbx6 levels and repression of alternative fates.

Activation of blood/endothelial gene expression programmes together with decreased plasticity allows consolidation of the blood fate and specification of the hematopoietic lineage

or definitive blood cells is not known as, to date, these two types of progenitors cannot be distinguished immunophenotypically or by gene expression.

Our findings have broad implications for our understanding of lineage determination. First, low level co-expression of Scl, Mesp1 and Tbx6 (required to specify blood, cardiac and paraxial lineages, respectively) confirms multi-lineage priming and suggests that progenitors can potentially adopt multiple fates. Existence of multilineage-primed cells agrees with studies showing that epiblast cells exhibit multipotency 48 and with observations of "transcriptional noise" in day E6.5 mouse epiblast cells ${ }^{49}$. Importantly, multi-lineage priming needs to be distinguished from multi-lineage potency. Even though Mesp1 and Tbx6 are coexpressed with $\mathrm{Scl}$ in blood-fated $\mathrm{FLK1}^{+}$cells, and, in absence of SCL, these cells can make cardiac and paraxial lineages, it is unclear if these cells are multi-potent at a clonal level in steady state, as multi-potency may only manifest in perturbed circumstances. One approach to address these open questions is to conduct in vivo fate tracing studies at appropriate developmental stages. This will characterise the extent of multi-potency and establish developmental relationships between mesodermal lineages.

Second, our data reveal the tight developmental window determining functional plasticity. Multi-lineage primed cells were most abundant in day 3.5 EBs and dramatically reduced at day 4.5. $\mathrm{FLK}^{+} \mathrm{Scl}^{-1-}$ cells gave rise to $\mathrm{PDGFRa}^{+}$cardiac/paraxial cells at day 3.5, but not at day 4.5. Finally, SCL activated Rybp and Pcgf5 expression at days $3.5 / 4$ only. In wild-type cells, plasticity is detected in cells expressing low levels of Scl, as only Scl:mCherry ${ }^{\text {low }}$ cells can adopt a cardiac fate at day 3.5, likely to be elicited by higher Mesp1 levels. This supports the notion of thresholddependent fate determination, as recently reported for the $\mathrm{TF}$ ETV2 in hemangiogenic fate specification ${ }^{50}$. At earlier stages of development, the trophectoderm and the inner cell mass also exhibit time-restricted plasticity ${ }^{51,52}$. This is believed to establish flexible gene regulatory networks based on heterogeneity of gene expression $^{53}$. Plasticity may therefore be a general property of cells undergoing lineage determination.

Third, our study reveals the importance of active repression of alternate fates in lineage-fated cells. To the best of our knowledge, we provide the first example of a single lineage-specific TF (SCL) directly regulating expression of $\mathrm{PcG}$ members during development. In so doing, SCL regulates PRC1 function, as shown by SCL-mediated global H2AK119 ubiquitination. Though PRC1 exhibits repressive roles during early embryonic development $\mathrm{t}^{1,45}$, somatic cell reprogramming 54 and haematopoietic development ${ }^{55}$, a function in lineage selection in germ layers has not been previously reported.

SCL activates expression of two specific PRC1 members, RYBP and PCGF5, both necessary for the function of ubiquitin ligase RING1B and full H2AK119 ubiquitination levels ${ }^{42,56}$. Thus, it is unsurprising that ubiquitination levels depend on SCL in bloodfated cells. Whilst our biochemical data indicate interaction between RYBP and SCL and co-localisation on a few genes, the mechanisms controlling RYBP recruitment and H2AK119ub deposition for most genes remain unclear. Interestingly, RYBPPRC1 target genes are usually expressed at higher levels than targets of canonical PRC1 complexes ${ }^{42}$. This suggests that ncPRC1 may cause incomplete gene expression silencing, thus permitting low-level gene expression and allowing lineage-fated cells to retain plasticity. Thereafter, ncPRC1 complexes could be replaced by more potent complexes, causing irreversible gene silencing and loss of plasticity.

Our work also reveals a complex pattern of gene regulation by SCL, ETO2 and RYBP. Indeed, ChIP-seq shows locus-specific binding of ETO2 and RYBP on SCL's 778 activated and repressed genes. Why would co-repressors bind to genes normally activated? One possibility is that co-repressors finely modulate gene expression levels, rather than simply repressing gene expression $^{57}$. This transcriptional flexibility could allow for rapid 
changes in transcription patterns to adapt to changing environments, and underlies cellular plasticity and transcriptional priming. What mechanisms dictate whether a gene is bound by any combination of SCL/ETO2/RYBP and whether it is activated or repressed remain important questions. Detailed analyses of specific gene loci are required.

Finally, our work highlights some of the relationships between histone marks, TF/co-factor binding and gene expression. Although the significance of SCL-dependent H2AK119 ubiquitination over extended genomic regions remains unclear, this observation is reminiscent of the wide "blanket" of Polycomb recruitment on the inactive $\mathrm{X}$ chromosome ${ }^{58}$, a paradigm of transcriptional repression. Based on the hierarchical model that PRC1 recruits PRC2 ${ }^{18}$, H2AK119Ub marks may facilitate recruitment of PRC2 and maintain high levels of $\mathrm{H} 3 \mathrm{~K} 27 \mathrm{me} 3$ at genes normally repressed in lowly acetylated chromatin. Genome-wide, high levels of ubiquitination also suggest that the default transcriptional state may be gene expression silencing. It is noteworthy that genes activated by SCL usually harbour multiple SCL binding sites, whilst repressed genes show much fewer binding events. Multiple SCL occupancy sites may be required to robustly recruit activating epigenetic complexes to overcome a globally repressive environment.

In conclusion, this study unveils the importance of transcriptional repression by a single tissue-specific regulator in multilineage primed cells and over tightly defined developmental windows during which lineage-specific gene expression programmes are initiated. Complex, gene-specific patterns of transcriptional regulation promote and repress lineage-affiliated gene expression to allow single lineage selection. These mechanisms are likely to be shared by other lineage-specific regulators in development and differentiation.

\section{Methods}

Single molecule RNA FISH (smRNA FISH). smRNA FISH was performed as described $^{59}$, with some alterations. In brief, oligonucleotide libraries (18-20 nucleotide-long) were designed using Stellaris Probe Designer to bind mainly to the ORF of each target mRNA ( 35 oligos for Scl, 29 oligos for Mesp1 and 38 oligos for $T b x 6)$ and synthesised with $3^{\prime}$ 3NHC6 modifications. They were pooled and labelled with Alexa NHS esters using Alexa-488 (Mesp1-Lifetech A20000), Alexa594 (Scl-Lifetech A37572) or Alexa-647 (Tbx6 and Gata4-Lifetech A37573) as described by the manufacturer. Only probes with a frequency of incorporation of $>90 \%$ (calculated with Geneflow nanophotometer) were used.

$100,000 \mathrm{~EB}$ cells were adhered to poly-L-Lysine-pre-coated coverslips (20 min, $37^{\circ} \mathrm{C}$ ). Cells were fixed in $4 \%$ Paraformaldehyde (PFA, $20 \mathrm{~min}$, room temperature $-\mathrm{RT}^{\circ}$ ), washed with PBS and permeabilised with $70 \% \mathrm{EtOH}$ (overnight $(\mathrm{o} / \mathrm{n}), 4^{\circ} \mathrm{C}$ ). After rehydration in wash buffer ( $2 \times$ SSC, $10 \%$ Formamide), cells were incubated with probes at a final concentration of $1 \mathrm{ng} / \mu \mathrm{l}$ in hybridisation buffer $(2 \times$ SSC, $10 \%$ Formamide, $10 \%$ Dextran Sulphate, $1 \mathrm{mg} \mathrm{ml}^{-1}$ tRNA, $2 \mathrm{mM}$ RNase inhibitor (RVC complex, NEB), $\left.0.2 \mathrm{mg} \mathrm{ml}^{-1} \mathrm{BSA}\right)$ in a humidity chamber $\left.(\mathrm{o} / \mathrm{n}), 30^{\circ} \mathrm{C}\right)$. Cells were then washed twice in wash buffer $\left(30 \mathrm{~min}, 30^{\circ} \mathrm{C}\right)$ and once in wash buffer + DAPI $0.5 \mu \mathrm{g} \mathrm{ml}^{-1}$ (Sigma, cat\# D9542) $30 \mathrm{~min}, 30^{\circ} \mathrm{C}$. Coverslips were mounted with Prolong Gold, which was allowed to polymerise o/n at RTo, in the dark, before imaging with a Delta Vision widefield microscope using a 100x oil objective.

Microscopy and data analysis. To avoid bleaching, smRNA FISH images were focused and taken based on DAPI stain only. For each image, a Z-stack of 53 images was acquired for all channels (DAPI, Alexa-488, Alexa-594 and Alexa-647). Image volumes were analysed using a Fiji/ImageJ macro script that automated the analysis (available upon request). Firstly, image volumes were Z-maximumprojected through a sub-range of the original slices; the sub-range was pre-chosen to best encapsulate the signal containing range of the cells within a dataset. Next, background fluorescence in the DAPI channel was removed from images by smoothing a copy of the maximum-projected image with a coarse Gaussian filter $($ sigma $=80)$ and subtracting this from the unsmoothed image. The filtered image was then thresholded to extract the nuclear regions. From this binary image, a Voronoi filter was applied to evenly split the image into regions based on the location of the nuclear centres. Each region was then assigned to the nucleus it encapsulated. Within each nuclei-associated region, the corresponding cell autofluorescence in the $488 \mathrm{~nm}$ channel was used to identify the cell. Segmentation was performed by thresholding the cellular fluorescence using an Otsu algorithm to convert the image into a binary representation, and then, using the "Watershed" algorithm, to split any larger objects. These cellular regions were then dissected using the Voronoi regions to split them up based on the distribution of nuclear centres. Regions of fluorescence within the thresholded auto-fluorescence channel and containing a corresponding DAPI signal were retained for further analysis; all other areas were discarded. This methodology provided an accurate means of obtaining cell regions even if more than one cell were touching and also removed artifactual stained non-cellular areas. Finally, within each cell, the channels containing the foci (Mesp1-A448, Scl-A594 or Tbx6-A647) were processed sequentially. All channels were smoothed with a Gaussian filter $($ sigma $=0.5)$ to reduce the impact of signal noise. Following this processing step, the signal intensities were identified and measured. The foci locations were identified using the ImageJ "Find Maxima" function with a simple filtering step to remove maxima that were too large to be foci ( $>40$ total pixel area). To avoid false positives, a specific point of cut off for positivity of 6 foci per cell was chosen after performing smRNA FISH on cells derived from ES cells knocked-out for the mRNAs of interest. Within these cells, the number of foci and also the average intensity level was measured from regions $(5 \times 5$ pixel $)$ centred on each foci. In addition, as a comparison, the intensity was also measured in regions surrounding the foci to give an idea of the background noise in these samples. These regions were selected by taking the coordinates of each true foci and then randomly perturbing the coordinates to find a region nearby (within 10 pixels) which did not overlap with any of the true foci locations. Data were exported to Excel for subsequent analysis and statistical testing.

Images shown in Fig. 1 and Supplementary Fig. 2 are maximum Z-stack projections of fluorescence images spanning the extent of the cells, in inverted black/white for Scl, Mesp1 and Tbx6. Within each subfigure, images from the same channel were adjusted equally, for direct comparison. Before compilation of experiments, a Stratified Kruskal-Wallis test was performed to check for significant differences, and none were found. To test for significant increases or decreases in cellular sub-types, a two-tailed Fisher's exact test was applied.

Embryonic stem (ES) cell culture and differentiation. Mouse ES cells (J1 wild-

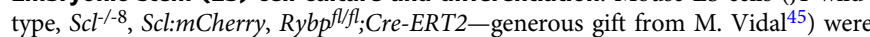
maintained in DMEM high glucose supplemented with $15 \%$ batch-selected fetal bovine serum (FBS), $2 \mathrm{mM}$ glutamine (Gibco/BRL), $2 \%$ LIF-conditioned medium and $1.5 \times 10^{-4} \mathrm{M}$ MTG. Twenty-four hours prior to differentiation, cells were passaged in LIF-containing IMDM medium. On the day of differentiation, 50,000-80,000 cells were seeded in $100 \mathrm{~mm}$ Petri Grade dishes in IMDM medium supplemented with $15 \%$ batch-selected FBS, $2 \mathrm{mM}$ glutamine, $300 \mu \mathrm{g} / \mathrm{ml}$ transferrin (Roche, cat\# 10652202001), $4.7 \times 10^{-4}$ M MTG (1-Thiolglycerol, Sigma, $\mathrm{M} 6145)$, and $50 \mu \mathrm{g} \mathrm{ml}^{-1}$ ascorbic acid. Cultures were maintained in a humidified incubator in $5 \% \mathrm{CO}_{2}$ /air at $37^{\circ} \mathrm{C}$.

Scl:mCherry cell lines. gRNAs (sequences are shown in Supplementary Table 1) were inserted into GFP-expressing pX458 or a derivative of pX330 (Addgene), by BbsI digestion and ligation. ES cells were transfected with gRNAs and a homology donor (sequences available upon request) using Nucleofector $2 \mathrm{~b}$ (Lonza) with programme A-013. $48 \mathrm{hrs}$ after transfection, single GFP-positive cells were sorted, clones expanded and checked for insertion by Sanger sequencing. The heterozygote Scl:mCherry cell line was generated from WT J1 cells using mCherry_gRNAs, and harbours the mCherry insertion on one allele. The $S c l^{\Delta / \Delta}: m$ Cherry cell line was engineered from the $S c l$ :mCherry cell line with mCherry $\Delta$ RNA1 and mCherry $\triangle$ gRNA2, and is homozygous for deletion of the bHLH domain.

siRNA and inhibitors. siRNAs-Day 2 WT EBs were transfected with $50 \mathrm{nM}$ siRNA against Eto2 (Darmacon, siGenome mouse Cbfa2t3 SMART pool, M042769) or Rybp (Darmacon, siGenome mouse Rybp SMART pool, M-042769) or with siRNA control (Darmacon, siGenome control pool, non-targeting, D-001206) using lipofectamine RNAimax (LifeTechnologies, cat\#13778) following the manufacturer's recommendations. At day 3.5, transfected cells were dissociated and replated in cardiac or blast colony assay. Gene expression was assessed by qRTPCR at days 3.5 and 4.5 .

Increasing concentrations PRC1 and PRC2 inhibitors were added at day 2 of EB differentiation. Day 3.5 EBs were dissociated for downstream functional assays or gene expression analysis. PRC1 inhibitor: PRT4165 (Tocris, cat\# 5047), PRC2 inhibitor: UNC1999 (Tocris, cat\# 4904) or the analogue UNC2400 (Tocris, cat\# 4905).

Hydroxytamoxifen treatment of Rybp fl/fl;Cre-ERT2 ES cells. Cells were treated at day 2 of EB differentiation with $0.8 \mu \mathrm{M}$ 4-hydroxytamoxifen (4-OHT) (Sigma, H7904). Fresh media was added after 18-24 h. 4-OHT-treated EBs were allowed to develop until day 3.5 when downstream assays were carried out.

Blast colony assay. $5 \times 10^{4}$ to $2 \times 10^{5}$ day $3.5 \mathrm{~EB}$ cells were seeded in $1 \%$ methylcellulose IMDM medium, supplemented with $300 \mu \mathrm{g} \mathrm{ml}^{-1}$ transferrin (Roche, cat\# 10652202001), $25 \mu \mathrm{g} \mathrm{ml}^{-1}$ ascorbic acid (Sigma, A-4544), $4 \times 10^{-4} \mathrm{M}$ MTG (1-Thiolglycerol, Sigma, M6145), 25\% D4T (endothelial cell) conditioned media, $5 \mathrm{ng} / \mathrm{ml}$ mouse VEGF, $5 \mathrm{ng} \mathrm{ml}^{-1}$ mouse interleukin 6 and $100 \mathrm{ng} \mathrm{ml}^{-1}$ mouse cKIT. Dishes were incubated in a humidified $5 \% \mathrm{CO}_{2}$ /air incubator and colonies scored at day $4^{60}$. All cytokines were purchased from Preprotech. 
Cardiac assay. Day 3.5 EB cells were replated at a density of 80,000 cells per gelatin-coated 96-well plate, in StemPro34 serum-free medium supplemented with $100 \mathrm{U} \mathrm{ml}^{-1}$ penicillin, $100 \mu \mathrm{g} \mathrm{ml}^{-1}$ streptomycin (Gico/BRL), $2 \mathrm{mM}$ glutamine (Gibco/BRL), $10 \mathrm{ng} \mathrm{ml}^{-1}$ human basic FGF, $12.5 \mathrm{ng} \mathrm{ml}^{-1}$ human FGF10, $5 \mathrm{ng} \mathrm{ml}^{-1}$ mouse VEGF and $1 \mathrm{mM}$ ascorbic acid (Sigma, A-4544) ${ }^{27}$. All growth factors were purchased from R\&D Systems. Medium was changed every other day until day 7 , when cultures were analysed.

Chondrogenic assay. After dissociation, single cell suspensions were seeded in chondrogenic medium (alpha-MEM supplemented with 10\% FBS, 1\% penicillin/ streptomycin, $0.1 \mu \mathrm{M}$ dexamethasone and $0.17 \mathrm{mM}$ ascorbic-acid 2-phosphate) with $10 \mathrm{ng} \mathrm{ml}^{-1}$ TGF $\beta 3$ for 6 days. On day 7, the medium was replaced with $10 \mathrm{ng} \mathrm{ml}^{-1}$ BMP2. The culture was kept for another two weeks with a medium change every 3 days. On day 21, alcian blue staining was performed. Cells were fixed with 4\% PFA for $30 \mathrm{~min}$, rinsed twice in PBS and once with water. Cultured cells were incubated in $0.05 \%$ alcian blue solution, $\mathrm{pH} 1.5\left(\mathrm{o} / \mathrm{n}, \mathrm{RT}^{\circ}\right)^{26}$. Presence of blue stained nodules were inspected by microscopy and cultures imaged on a microscope (BX60; Olympus) with a Q Imaging camera and OpenLab (Improvision) software.

Antibodies. References and conditions of use of all antibodies employed in this study are shown in Supplementary Table 2.

Immunofluorescence. Cells were fixed in 4\% PFA for 10 mins on ice, washed three times in PBS (5 mins, $\left.\mathrm{RT}^{\circ}\right)$. They were then blocked and permeabilised in $0.2 \%$ Triton $\mathrm{X}-100 / \mathrm{PBS}$ containing 10\% donkey serum (Sigma, D9663), $1 \mathrm{~h}$ at RT ${ }^{\circ}$. Cells were incubated with primary antibody in $0.2 \%$ Triton X-100/PBS containing $1 \%$ donkey serum $\left(\mathrm{o} / \mathrm{n}, 4^{\circ} \mathrm{C}\right)$. After three washes of $5 \mathrm{~min}$ at $\mathrm{RT}^{\circ}$, cells were incubated $1 \mathrm{~h}$ at $\mathrm{RT}^{\circ}$ with donkey-raised secondary antibody in $0.2 \%$ Triton X-100/PBS containing $1 \%$ donkey serum and $0.5 \mu \mathrm{g} \mathrm{ml}^{-1}$ DAPI. Cells were washed $3 \times$ in PBS for $5 \mathrm{~min}$ and visualised on Zeiss 880 inverted confocal microscope. Primary antibodies: cTNT (Abcam, 1C11, $10 \mu \mathrm{g} \mathrm{ml}^{-1}$ ), CD31 (R\&D systems, AF3628, $2 \mu \mathrm{g} \mathrm{ml}^{-1}$ ) and ColIIa (DSHB, II-II6B3, $5 \mu \mathrm{g} \mathrm{ml}^{-1}$ ). Secondary antibodies: Alexa-488 donkey anti-mouse (A21202, $6 \mu \mathrm{g} \mathrm{ml}^{-1}$ ), Alex-555 donkey anti-goat (Thermofisher A-21432; $5 \mu \mathrm{g} \mathrm{ml}^{-1}$ ).

Mice. All animal work was carried out under appropriate project licences according to UK Home Office regulations and approved by the Oxford University Committee on Animal Care and Ethical Review. E9.5 embryos were harvested and dissected to collect yolk sacs. Tissues were incubated in $0.125 \%$ collagenase (Sigma, C0130) solution to achieve single cell suspensions $\left(15 \mathrm{~min}, 37^{\circ} \mathrm{C}\right)$. Each individual yolk sac was replated in cardiac or chondrogenic medium on an OP9 layer.

Quantitative RT-PCR. Total RNA was extracted with Qiagen kits and DNasetreated on column. $500 \mathrm{ng}$ to $1 \mu \mathrm{g}$ of total RNA was converted into cDNA using Omniscript (Qiagen). For quantitative real-time expression analysis, qPCR reactions were performed using TaqMan universal PCR mastermix (Life Technologies, cat\# 4304437) and TaqMan gene expression assays (Life Technologies). For Gapdh and Gatal genes, primers/probes were designed using Primer Express v3 software and purchased from Eurogentec. References for all primers and probes used in Taqman assays are shown in Supplementary Table 3. Expression levels were calculated relative to a control sequence in the Gapdh gene. All reactions were performed in duplicate using Sequence Detection System 7000 Thermocycler (Applied Biosystems)

Immunoprecipitation (IP). EBs were dissociated and resuspended in Buffer A (10 $\mathrm{mM}$ HEPES $\mathrm{pH} 7.9,1.5 \mathrm{mM} \mathrm{MgCl} 2,10 \mathrm{mM} \mathrm{KCl}$, and proteinase inhibitors), kept on ice for $10 \mathrm{~min}$, and centrifuged for $10 \mathrm{~s}$ at $13,500 \mathrm{rpm}$. The nuclear pellet was resuspended in 0.5\% TritonX-100/RSB100 (10 mM Tris pH 8.0, $100 \mathrm{mM} \mathrm{NaCl}, 2.5$ $\mathrm{mM} \mathrm{MgCl}$, proteinase inhibitors), vortexed on/off for $30 \mathrm{~min}$, kept on ice in between. Extracts were rotated to release chromatin-bound SCL (5U Benzonase/1 $\mu \mathrm{l}$ extract for $\left.1 \mathrm{~h}, 4^{\circ} \mathrm{C}\right)$. Samples were centrifuged $\left(4000 \mathrm{rpm}, 15 \mathrm{~min}, 4^{\circ} \mathrm{C}\right)$ and the supernatant was treated with RNase A $\left(100 \mu \mathrm{g} \mathrm{ml}^{-1}, 2-3 \mathrm{~min}\right)$ before centrifugation $(13,500 \mathrm{rpm}, 1 \mathrm{~min})$ to prevent RNA-mediated carryover. The supernatant contained the soluble nuclear extracts. For IPs, nuclear extracts were precleared with Protein $\mathrm{G}$ dynabeads for $30 \mathrm{~min}$, before incubation with antibody pre-bound to Protein G dynabeads for $3 \mathrm{~h}$ (SCL) or o/n (RING1B and RYBP). Beads were washed $4 \times$ in $0.5 \%$ TritonX-100/RSB100 and eluted with $1 \times$ LDS $\left(10 \mathrm{~min}, 70^{\circ} \mathrm{C}\right)$.

Western blotting. Samples were run on a $4-12 \%$ precast Bis-tris gel, and transferred to a activated PVDF membrane (IPVH00010, Merck). The membrane was blocked in 5\% skimmed milk/PBS, and incubated in primary antibody $1 \mathrm{~h}$ in $5 \%$ skimmed milk/PBS, washed four times in $0.05 \%$ tween/PBS, incubated in secondary antibody $1 \mathrm{~h}$ in $5 \%$ skimmed milk/PBS, washed as before and developed with the ECL prime western blotting detection kit (RPN2232, GE healthcare Life sciences). For histones, $10^{6}$ cells were lysed in $20 \mathrm{mM}$ Tris, pH 7.4, $20 \mathrm{mM}$ EDTA, $\mathrm{pH} 8,2 \%$ SDS and $20 \%$ glycerol, boiled for $5 \mathrm{~min}$ and sonicated on Bioruptor Plus. Semi-quantitation of the protein bands was performed using the Biorad Chemi doc MP imaging system.

Uncropped scans are shown in Supplementary Figs. 8 and 9.
Flow cytometry and cell sorting. Cells were stained with PE-conjugated antiFLK1 and APC-conjugated anti-PDGFR $\alpha$ antibodies (eBioscience cat\# 12-5821-83 and 17-1401-81) for $20 \mathrm{~min}$ at $4^{\circ} \mathrm{C}$, washed and sorted on BD FACS Aria II (Becton Dickinson) or Sony SH800 FACS sorter.

SCL intracellular FACS. Cells were stained with live/dead stain kit (Thermofisher, L34955) for $20 \mathrm{~min}$, fixed in 2\% PFA and permeabilised in $0.1 \%$ Triton X-100. Cells were stained with anti-SCL antibody (Santa Cruz, clone C21) conjugated to Alexa488 (Zenon Alexafluor-488 goat IgG labelling kit, Invitrogen, cat\# Z25602) following manufacturer's instructions.

cTNT intracellular FACS. Cardiac cultures were dissociated using 0.25\% trypsin/ EDTA (Gibco/BRL) for $5 \mathrm{~min}$ at $37^{\circ} \mathrm{C}$ to quickly lift the monolayer cells off the plate, then a single cell suspension was achieved with a solution of collagenase/ DNase (PBS with $20 \%$ serum, $10 \mathrm{mg} \mathrm{ml}^{-1}$ collagenase A (Roche, cat\#11088785103), $10 \mathrm{mg} \mathrm{ml}^{-1}$ collagenase B and $10 \mu \mathrm{g} \mathrm{ml}^{-1}$ DNase I (Roche, cat 1184932001), $5-10 \mathrm{~min}$ at $37^{\circ} \mathrm{C}$. Cells were stained with live/dead stain (Thermofisher, cat\# L34955) for 20 min, fixed in 2\% PFA and permeabilised in $0.5 \%$ saponin (Sigma, cat\# S7900). After a wash in PBS/0.1\% saponin, cells were stained with anti-cTNT (Abcam, clone 1C11) primary antibody and Alexa-488 donkey anti-mouse (Thermofisher, cat\# A21202) secondary antibody.

Isolation of FLK1 ${ }^{+}$cells. Day 3.5/4 EB cells were stained with PE-conjugated FLK1 antibody (eBioscience) for $20 \mathrm{~min}$. After a wash in PBS/FCS, cells were incubated with anti-PE microbeads (Miltenyi) for $15 \mathrm{~min}$. FLK1 ${ }^{+}$cells were isolated on Myltenyi magnetic columns.

Single-cell RNA sequencing analysis. Single cell RNA-seq read-count tables obtained from mouse embryos at different stages of development (days E6.5 to E7.75) were downloaded from http://gastrulation.stemcells.cam.ac.uk/scialdone2016 ${ }^{14}$. The data passed the quality control and cell filtering processes described in the ref. ${ }^{14}$. The $\mathrm{R}$-script for the t-distributed stochastic neighbour embedding ( $\mathrm{t}-\mathrm{SNE}$ ) analysis of different cell stages was kindly provided by A. Scialdone, and the 'Rtsne' function from the Rtsne package with the input from highly variable genes was used (see Method section in the ref. ${ }^{14}$ ). To match day 3.5 EB cells to the distinct cell populations identified at different stages of mouse embryonic development, we selected 18 embryonic development-related genes highly expressed in day 3.5 EBs and superimposed the average gene expression of these genes (gene score) to visualise the enrichment on the t-SNE plot.

RNAseq. WT and $\mathrm{Scl}^{-/-}$day $3.5 \mathrm{FLK1}^{+}$EB cells were isolated and total RNA extracted. Library generation and sequencing were performed at Oxford Genomics Centre (Wellcome Trust Centre of Human Genetics). Fastq reads were aligned to the $\mathrm{mm} 9$ reference genome using tophat version $2.0 .8 \mathrm{~b}^{61}$. Duplicate read pairs were removed, and reads filtered for mapq $>15$ using SAMtools version 0.1.1961. Data normalisation and differential expression analysis was carried out using edge ${ }^{62}$. Data normalisation to account for differences in sequencing depth and RNA composition was performed using the TMM method (trimmed mean of $M$ values $^{63}$ ), provided by the edgeR package. Gene lists were analysed for biological processes using PANTHER overrepresentation test ${ }^{64}$

Chromatin immunoprecipitation (ChIP). For SCL, ETO2 and RYBP ChIP, 2-5× $10^{7}$ day 3.5 (SCL) and day 4 (ETO2/RYBP) $\mathrm{FLK1}^{+}$cells were fixed $20 \mathrm{~min}, \mathrm{RT}^{\circ}$ with $2 \mathrm{mM}$ EGS (ethylene glycol bis succinimidylsuccinate, ThermoFisher Scientific, cat\# 10350924) followed by $1 \%$ Formaldehyde (Sigma, 252549) incubation for $10 \mathrm{~min}$ under gentle agitation before quenching with $0.125 \mathrm{M}$ glycine. Cells were rinsed twice with PBS, lysed, and chromatin sonicated to an average size of 300 base pairs using Bioruptor Plus (Diagenode) at Power 3.0 for 17 cycles ( $30 \mathrm{~s} \mathrm{ON}$, $30 \mathrm{~s}$ OFF). The resulting chromatin was diluted $10 \times$ in ChIP dilution buffer and $1 \%$ put aside as input sample. After pre-clearing with protein A/G dynabeads (ThermoFisher Scientific), supernatants were incubated with appropriate antibodies o/n Beads were washed in low salt/high salt $\mathrm{LiCl}$ buffers and twice with Tris/EDTA. Complexes were eluted from beads in a thermomixer $\left(65^{\circ} \mathrm{C}, 15 \mathrm{~min}\right)$ and eluates and reserved inputs reverse cross-linked $\left(65^{\circ} \mathrm{C}, \mathrm{o} / \mathrm{n}\right)$. Samples were treated with RNaseA, proteinase $\mathrm{K}$ and phenol/chloroform-purified.

ChIP-sequencing. ChIP samples were submitted to library preparation using NEBNext Ultra DNA Library prep kit and multiplexing barcodes (NEB, E7370) following Illumina's instructions. Samples were quantified by the KAPA Library Quantification Kit (Roche diagnostics, cat\# 7960140001) and their sizes verified on a Bioanalyser 2100 (Agilent). Libraries were sequenced using NextSeq v2 kit (75 cycles, Illumina, FC-404-2005) on a NextSeq 550 system with paired-end reads for 37 cycles. Sequences were de-multiplexed, aligned to the Mus musculus (mm9) genome using Bowtie (version 1.1.2), and filtered to remove duplicate mapped reads. Peak calling was performed with MACS2 (version 2.0.10) using default parameters for SCL and ETO2 ChIP; the broad option was applied for RYBP ChIP MIG (Multi-Image Genome viewer) was used to visualise the data, filter and identify peaks ${ }^{65}$. Data for heatmaps and meta gene plots were generated using 
HOMER annotatePeaks command and visualised with Java_Treeview. GO analysis of genomic regions was performed with Stanford GREAT online tool ${ }^{66}$. The ATAC-seq procedure and data will be reported somewhere else.

Histone ChIP-sequencing-Rx. Histone ChIPSeq-Rx was carried out according to published protocols $\mathrm{s}^{37}$. Briefly, day 4 mCherry-positive sorted cells were mixed in a 2:1 ratio to Drosophila S2 cells. Samples were prepared and sequencing was performed as above. Data were mapped using an in-house pipeline. Reads were aligned to Mus musculus (mm9) and Drosophila melanogaster (dm3) genomes. The number of reads mapping to the genomes as well as the derived normalisation factor for each histone mark are provided in Supplementary Data 4. Peak calling was performed using MACS2 (version 2.0.10) using parameters for broad peak calling and respective inputs as reference. Tag directories were created using Homer and the generated BedGraphs were visualised on UCSC Genome Browser as custom tracks, after scaling the tag densities by the normalisation factor for each histone mark. Histograms and heatmaps were generated using AnnotatePeaks.pl command with up to $-100 \mathrm{~kb}$ to $100 \mathrm{~kb}$ around the indicated genomic regions separated into 25 equally sized bin; the ChIP fragment coverage was scaled by the derived normalisation factor.

Code availability. All codes used in this study can be accessed from the GEO database (accession number GSE104883).

\section{Data availability}

All ChIP-seq and RNA-seq datasets are deposited at the NCBI GEO database under the accession number GSE104883. All other data supporting the results of this study are available within the article and its supplementary information files and from the corresponding author upon request. A reporting summary is available as a Supplementary Information file.

Received: 24 March 2018 Accepted: 23 November 2018

Published online: 18 December 2018

\section{References}

1. Arnold, S. J. \& Robertson, E. J. Making a commitment: cell lineage allocation and axis patterning in the early mouse embryo. Nat. Rev. Mol. Cell Biol. 10, 91-103 (2009).

2. Robertson, E. J. Dose-dependent Nodal/Smad signals pattern the early mouse embryo. Semin. Cell. Dev. Biol. 32, 73-79 (2014).

3. Tam, P. P., Parameswaran, M., Kinder, S. J. \& Weinberger, R. P. The allocation of epiblast cells to the embryonic heart and other mesodermal lineages: the role of ingression and tissue movement during gastrulation. Development 124, 1631-1642 (1997).

4. Kinder, S. J. et al. The orderly allocation of mesodermal cells to the extraembryonic structures and the anteroposterior axis during gastrulation of the mouse embryo. Development 126, 4691-4701 (1999).

5. Porcher, C., Chagraoui, H. \& Kristiansen, M. S. SCL/TAL1: a multifaceted regulator from blood development to disease. Blood 129, 2051-2060 (2017).

6. Ema, M. et al. Combinatorial effects of Flk1 and Tall on vascular and hematopoietic development in the mouse. Genes Dev. 17, 380-393 (2003).

7. Shivdasani, R. A., Mayer, E. L. \& Orkin, S. H. Absence of blood formation in mice lacking the T-cell leukaemia oncoprotein tal-1/SCL. Nature 373, 432-434 (1995).

8. Porcher, C. et al. The T cell leukemia oncoprotein SCL/tal-1 is essential for development of all hematopoietic lineages. Cell 86, 47-57 (1996).

9. Schoenebeck, J. J., Keegan, B. R. \& Yelon, D. Vessel and blood specification override cardiac potential in anterior mesoderm. Dev. Cell 13, 254-267 (2007).

10. Van Handel, B. et al. Scl represses cardiomyogenesis in prospective hemogenic endothelium and endocardium. Cell 150, 590-605 (2012).

11. Org, T. et al. Scl binds to primed enhancers in mesoderm to regulate hematopoietic and cardiac fate divergence. EMBO J. 34, 759-777 (2015).

12. Gering, M., Yamada, Y. \& Rabbitts, T. H. \& Patient, R.K. Lmo2 and Scl/Tall convert non-axial mesoderm into haemangioblasts which differentiate into endothelial cells in the absence of Gatal. Development 130, 6187-6199 (2003).

13. Ismailoglu, I., Yeamans, G., Daley, G. Q., Perlingeiro, R. C. \& Kyba, M. Mesodermal patterning activity of SCL. Exp. Hematol. 36, 1593-1603 (2008).

14. Scialdone, A. et al. Resolving early mesoderm diversification through singlecell expression profiling. Nature 535, 289-293 (2016).

15. El Omari, K. et al. Structural basis for LMO2-driven recruitment of the SCL: E47bHLH heterodimer to hematopoietic-specific transcriptional targets. Cell Rep. 4, 135-147 (2013).

16. Aloia, L., Di Stefano, B. \& Di Croce, L. Polycomb complexes in stem cells and embryonic development. Development 140, 2525-2534 (2013).

17. Vidal, M. \& Starowicz, K. Polycomb complexes PRC1 and their function in hematopoiesis. Exp. Hematol. 48, 12-31 (2017).
18. Blackledge, N. P., Rose, N. R. \& Klose, R. J. Targeting polycomb systems to regulate gene expression: modifications to a complex story. Nat. Rev. Mol. Cell Biol. 16, 643-649 (2015).

19. Keller, G. Embryonic stem cell differentiation: emergence of a new era in biology and medicine. Genes Dev. 19, 1129-1155 (2005).

20. Shalaby, F. et al. A requirement for Flk1 in primitive and definitive hematopoiesis and vasculogenesis. Cell 89, 981-990 (1997).

21. Bondue, A. \& Blanpain, C. Mesp1: a key regulator of cardiovascular lineage commitment. Circ. Res. 107, 1414-1427 (2010).

22. Chapman, D. L. \& Papaioannou, V. E. Three neural tubes in mouse embryos with mutations in the T-box gene Tbx6. Nature 391, 695-697 (1998).

23. Saga, Y. et al. MesP1: a novel basic helix-loop-helix protein expressed in the nascent mesodermal cells during mouse gastrulation. Development 122, 2769-2778 (1996).

24. Chan, S. S. et al. Mesp1 patterns mesoderm into cardiac, hematopoietic, or skeletal myogenic progenitors in a context-dependent manner. Cell Stem Cell 12, 587-601 (2013).

25. Nishikawa, S. I., Nishikawa, S., Hirashima, M., Matsuyoshi, N. \& Kodama, H. Progressive lineage analysis by cell sorting and culture identifies FLK1+ VEcadherin + cells at a diverging point of endothelial and hemopoietic lineages. Development 125, 1747-1757 (1998).

26. Sakurai, $H$. et al. In vitro modeling of paraxial and lateral mesoderm differentiation reveals early reversibility. Stem Cells 24, 575-586 (2006).

27. Kattman, S. J. et al. Stage-specific optimization of activin/nodal and BMP signaling promotes cardiac differentiation of mouse and human pluripotent stem cell lines. Cell Stem Cell 8, 228-240 (2011).

28. Magli, A. et al. Pax 3 and Tbx5 specify whether PDGFRalpha+ cells assume skeletal or cardiac muscle fate in differentiating embryonic stem cells. Stem Cells 32, 2072-2083 (2014).

29. Jaffredo, T., Gautier, R., Eichmann, A. \& Dieterlen-Lievre, F. Intraaortic hemopoietic cells are derived from endothelial cells during ontogeny. Development 125, 4575-4583 (1998).

30. Hirai, H. et al. Involvement of Runxl in the downregulation of fetal liver kinase-1 expression during transition of endothelial cells to hematopoietic cells. Blood 106, 1948-1955 (2005).

31. Schlaeger, T. M. et al. Decoding hematopoietic specificity in the helix-loophelix domain of the transcription factor SCL/Tal-1. Mol. Cell. Biol. 24, 7491-7502 (2004).

32. Ogilvy, S. et al. The SCL +40 enhancer targets the midbrain together with primitive and definitive hematopoiesis and is regulated by SCL and GATA proteins. Mol. Cell. Biol. 27, 7206-7219 (2007).

33. Akiyama, H., Chaboissier, M. C., Martin, J. F., Schedl, A. \& de Crombrugghe, B. The transcription factor Sox 9 has essential roles in successive steps of the chondrocyte differentiation pathway and is required for expression of Sox 5 and Sox6. Genes Dev. 16, 2813-2828 (2002).

34. Barna, M. \& Niswander, L. Visualization of cartilage formation: insight into cellular properties of skeletal progenitors and chondrodysplasia syndromes. Dev. Cell 12, 931-941 (2007).

35. D'Souza, S. L., Elefanty, A. G. \& Keller, G. SCL/Tal-1 is essential for hematopoietic commitment of the hemangioblast but not for its development. Blood 105, 3862-3870 (2005).

36. Schuh, A. H. et al. ETO-2 associates with SCL in erythroid cells and megakaryocytes and provides repressor functions in erythropoiesis. Mol. Cell. Biol. 25, 10235-10250 (2005)

37. Orlando, D. A. et al. Quantitative ChIP-Seq normalization reveals global modulation of the epigenome. Cell Rep. 9, 1163-1170 (2014).

38. Huang, S., Qiu, Y., Stein, R. W. \& Brandt, S. J. p300 functions as a transcriptional coactivator for the TAL1/SCL oncoprotein. Oncogene 18, 4958-4967 (1999).

39. Hamlett, I. et al. Characterization of megakaryocyte GATA1-interacting proteins: the corepressor ETO2 and GATA1 interact to regulate terminal megakaryocyte maturation. Blood 112, 2738-2749 (2008).

40. Stadhouders, R. et al. Control of developmentally primed erythroid genes by combinatorial co-repressor actions. Nat. Commun. 6, 8893 (2015).

41. Tavares, L. et al. RYBP-PRC1 complexes mediate H2A ubiquitylation at polycomb target sites independently of PRC2 and H3K27me3. Cell 148, 664-678 (2012).

42. Morey, L., Aloia, L., Cozzuto, L., Benitah, S. A. \& Di Croce, L. RYBP and Cbx7 define specific biological functions of polycomb complexes in mouse embryonic stem cells. Cell Rep. 3, 60-69 (2013).

43. Gao, Z. et al. PCGF homologs, CBX proteins, and RYBP define functionally distinct PRC1 family complexes. Mol. Cell 45, 344-356 (2012).

44. Kassouf, M. T. et al. Genome-wide identification of TAL1's functional targets: insights into its mechanisms of action in primary erythroid cells. Genome Res. 20, 1064-1083 (2010).

45. Hisada, K. et al. RYBP represses endogenous retroviruses and preimplantation- and germ line-specific genes in mouse embryonic stem cells. Mol. Cell. Biol. 32, 1139-1149 (2012). 
46. Ismail, I. H., McDonald, D., Strickfaden, H., Xu, Z. \& Hendzel, M. J. A small molecule inhibitor of polycomb repressive complex 1 inhibits ubiquitin signaling at DNA double-strand breaks. J. Biol. Chem. 288, 26944-26954 (2013).

47. Konze, K. D. et al. An orally bioavailable chemical probe of the Lysine Methyltransferases EZH2 and EZH1. ACS Chem. Biol. 8, 1324-1334 (2013).

48. Lawson, K. A., Meneses, J. J. \& Pedersen, R. A. Clonal analysis of epiblast fate during germ layer formation in the mouse embryo. Development 113, 891-911 (1991).

49. Mohammed, H. et al. Single-cell landscape of transcriptional heterogeneity and cell fate decisions during mouse early gastrulation. Cell Rep. 20, 1215-1228 (2017).

50. Zhao, H. \& Choi, K. A CRISPR screen identifies genes controlling Etv2 threshold expression in murine hemangiogenic fate commitment. Nat. Commun. 8, 541 (2017).

51. Posfai, E. et al. Position- and Hippo signaling-dependent plasticity during lineage segregation in the early mouse embryo. eLife 6, pii: e22906 (2017).

52. Grabarek, J. B. et al. Differential plasticity of epiblast and primitive endoderm precursors within the ICM of the early mouse embryo. Development 139, 129-139 (2012).

53. Martinez Arias, A., Nichols, J. \& Schroter, C. A molecular basis for developmental plasticity in early mammalian embryos. Development 140, 3499-3510 (2013).

54. $\mathrm{Li}, \mathrm{H}$. et al. RNA helicase DDX5 inhibits reprogramming to pluripotency by miRNA-based repression of RYBP and its PRC1-dependent and -independent functions. Cell Stem Cell 20, 462-477 e466 (2017).

55. Eliades, A. et al. The hemogenic competence of endothelial progenitors isrestricted by Runx1 silencing during embryonic development. Cell Rep. 15, 2185-2199 (2016).

56. $\mathrm{Si}, \mathrm{S}$. et al. Loss of Pcgf5 affects global H2A monoubiquitination but not the function of hematopoietic stem and progenitor cells. PLOS ONE 11, e0154561 (2016).

57. Reynolds, N., O’Shaughnessy, A. \& Hendrich, B. Transcriptional repressors: multifaceted regulators of gene expression. Development 140, 505-512 (2013).

58. Brockdorff, N. Polycomb complexes in X chromosome inactivation. Philos. Trans. R. Soc. Lond. B 372, pii: 20170021 (2017).

59. Lyubimova, A. et al. Single-molecule mRNA detection and counting in mammalian tissue. Nat. Protoc. 8, 1743-1758 (2013).

60. Kassouf, M. T., Chagraoui, H., Vyas, P. \& Porcher, C. Differential use of SCL/ TAL-1 DNA-binding domain in developmental hematopoiesis. Blood 112, 1056-1067 (2008).

61. Kim, D. et al. TopHat2: accurate alignment of transcriptomes in the presence of insertions, deletions and gene fusions. Genome Biol. 14, R36 (2013).

62. McCarthy, D. J., Chen, Y. \& Smyth, G. K. Differential expression analysis of multifactor RNA-Seq experiments with respect to biological variation. Nucleic Acids Res. 40, 4288-4297 (2012).

63. Robinson, M. D. \& Oshlack, A. A scaling normalization method for differential expression analysis of RNA-seq data. Genome Biol. 11, R25 (2010).

64. Mi, H., Muruganujan, A., Casagrande, J. T. \& Thomas, P. D. Large-scale gene function analysis with the PANTHER classification system. Nat. Protoc. 8, 1551-1566 (2013).

65. McGowan, S. J., Hughes, J. R., Han, Z. P. \& Taylor, S. MIG: multi-image genome viewer. Bioinformatics 29, 2477-2478 (2013).

66. McLean, C. Y. et al. GREAT improves functional interpretation of cisregulatory regions. Nat. Biotechnol. 28, 495-501 (2010).

\section{Acknowledgements}

We are grateful to Tom Milne for helpful discussions and critical reading of the manuscript. We thank Veronica Buckle and Jill Brown for advice on smRNA FISH, Jelena M. Telenius for use of her ChIP-sequencing analysis pipeline and Jon Kerry for help with the bioinformatics analysis. We acknowledge Christoffer Lagerholm (Wolfson Imaging Centre, Oxford) for his help with imaging smRNA FISH data. The imaging facility is supported by the MRC via the WIMM Strategic Alliance (G0902418 and MC_UU_12025), the Molecular Haematology Unit (MC_UU_12009), the Human Immunology Unit (MC_UU_12010), the Wolfson Foundation (Grant 18272), and by an MRC/BBSRC/EPSRC grant (MR/K015777X/1) to MICA - Nanoscopy Oxford (NanO). We thank the high-throughput Genomics Group at the Wellcome Trust Centre for Human Genetics (funded by Wellcome Trust grant 090532/Z/09/Z and MRC Hub grant G0900747 91070) for the generation of SCL ChIP-seq data. We thank Miguel Vidal for providing the Rybffl/fl;Cre-ERT2 mouse ES cells. This work was supported by the MRC (grant MC_UU_12009/9 to C.P.).

\section{Author contributions}

C.P. conceived the study. H.C., M.S.K. and C.P designed and analysed experiments. H.C., M.S.K., J.P.R., A.S-B., J.R. and E.H-P. performed experiments. H.C., N.G., D.W., E.R., G. O., S.T. and S.Th. carried out computational analyses. K.C., P.H. and P.S. provided expert technical help. C.P., H.C., M.S.K. and P.V. wrote the manuscript.

\section{Additional information}

Supplementary Information accompanies this paper at https://doi.org/10.1038/s41467018-07787-6.

Competing interests: The authors declare no competing interests.

Reprints and permission information is available online at http://npg.nature.com/ reprintsandpermissions/

Publisher's note: Springer Nature remains neutral with regard to jurisdictional claims in published maps and institutional affiliations.

Open Access This article is licensed under a Creative Commons Attribution 4.0 International License, which permits use, sharing, adaptation, distribution and reproduction in any medium or format, as long as you give appropriate credit to the original author(s) and the source, provide a link to the Creative Commons license, and indicate if changes were made. The images or other third party material in this article are included in the article's Creative Commons license, unless indicated otherwise in a credit line to the material. If material is not included in the article's Creative Commons license and your intended use is not permitted by statutory regulation or exceeds the permitted use, you will need to obtain permission directly from the copyright holder. To view a copy of this license, visit http://creativecommons.org/ licenses/by/4.0/.

(C) The Author(s) 2018 